\title{
Distributed Energy Systems Integration and Demand Optimization for Autonomous Operations and Electric Grid Transactions
}

\author{
Girish Ghatikar ${ }^{1,2}$, Salman Mashayekh ${ }^{1}$, Michael Stadler ${ }^{1,3}$, Rongxin Yin ${ }^{1}$, and Zhenhua Liu ${ }^{1}$ \\ ${ }^{1}$ Lawrence Berkeley National Laboratory, Berkeley, USA \\ ${ }^{2}$ Greenlots, San Francisco, USA \\ ${ }^{3}$ Center for Energy and innovative Technologies, Austria \\ Email corresponding author: mstadler@lbl.govor mstadler@cet.or.at
}

\begin{abstract}
Distributed power systems in the U.S. and globally are evolving to provide reliable and clean energy to consumers. In California, existing regulations require significant increases in renewable generation, as well as identification of customer-side distributed energy resources (DER) controls, communication technologies, and standards for interconnection with the electric grid systems. As DER deployment expands, customer-side DER control and optimization will be critical for system flexibility and demand response (DR) participation, which improves the economic viability of DER systems. Current DER systems integration and communication challenges include leveraging the existing DER and DR technology and systems infrastructure, and enabling optimized cost, energy and carbon choices for customers to deploy interoperable grid transactions and renewable energy systems at scale.

This paper presents a cost-effective solution to these challenges by exploring communication technologies and information models for DER system integration and interoperability. This system uses open standards and optimization models for resource planning based on dynamic-pricing notifications and autonomous operations within various domains of the smart grid energy system. It identifies architectures and customer engagement strategies in dynamic DR pricing transactions to generate feedback information models for load flexibility, load profiles, and participation schedules. The models are tested at a real site in California-Fort Hunter Liggett (FHL). The results for FHL show that the model fits within the existing and new DR business models and networked systems for transactive energy concepts. Integrated energy systems, communication networks, and modeling tools that coordinate supply-side networks and DER will enable electric grid system operators to use DER for grid transactions in an integrated system.
\end{abstract}

\section{Keywords}

Electric grid transactions, distributed energy resources, smart grid integration, microgrids, dynamic optimization, integrated energy systems optimization

\section{Introduction}

Clean energy generation and power systems in the U.S. are evolving to provide reliable energy to consumers. Some states have more aggressive clean and Distributed Energy Resources (DER) goals. For example, California's energy generation goals require 33 percent of annual retail sales from renewable sources by 2020, 12 gigawatts (GW) of distributed generation (DG) by 2020, and one million solar rooftops by 2018 [1]. The California Public Utilities Commission (CPUC) Rule 21 requires identification of customer-side DER controls, communication technologies, and standards for grid connectivity [2]. California requires over $4 \mathrm{GW}$ of ancillary services (fast dispatch) and costeffective energy storage to meet 2020 clean energy generation goals [3]. 
In a continuing effort to meet the clean energy generation goals set forth by states such as California, the renewable generation capacity, from both the grid (supply) and customers (demand) was 21,000 megawatts (MW) [4] at the end of 2014. This generation mix includes roughly 100,000 customer installations of solar PV. In addition to local cost, energy, and carbon savings, the distributed generation resources' ability to act as a DR resource for electric grid transactions should be considered. Over $250 \mathrm{MW}$ of DR automation, mostly on the building side and not on the generation side, is enrolled in California utilities' DR programs using a national and industry-supported open standard: OpenADR [5]. With increased adoption of DER such as CHP, storage, on-site generation, and others, there is need for optimized DR planning based on dynamic pricing DR programs (e.g., day-ahead PDP/CPP and RTP) and standardized data models involving DG. The availability of DER to provide DR transactions to utility DR programs depends on the timescales of DR and market requirements. Day-ahead dynamic prices can be considered to identify DR availability, and they are deployed by a majority of California's AutoDR programs. The key challenges for DER to participate in electricity markets are to:

- understand the existing electricity markets and their role in the next generation grid,

- leverage the existing DER technology infrastructure,

- enable customers to optimize cost and energy, as well as carbon minimization choices, and

- $\quad$ provide dynamic feedback between customers and utilities or electric grid operators.

Customer-side DER interactions have not been considered in most demand response (DR) transactions. Also, the DR programs offered by most service providers in the U.S. rely on static predetermined DR values (i.e., $x$ kilowatts) from the customer, typically under a contract and are estimated after the DR event happens. If the customer does not deliver the contracted DR, service providers cannot rely on a reliable and persistent response from the demand-side and will resort to expensive or less carbon-friendly supply-side resources. In this context, we refer reliability to customer's DR performance, which closely matches the predetermined DR values, and persistency refers to customer DR participation in all events with a reliable response. Electricity service providers can rely on $\mathrm{DR}$ as a resource when it starts to offer the reliability and persistency of supply-side generation. The existing programs and automation solutions have not solved the performance problem because of the static approach, which still remains a significant challenge [6, 7].

This first of its kind study evaluates the role of dynamic model-in-the-loop simulations and end-to-end automation to identify customers' DR strategies, involving customer side DER, to achieve reliable and persistent responses from customers' DER and encourage their integration with the electricity markets. The dynamic model in the loop simulation refers to a new approach that provides a real-time feedback of DR schedules and availability to the electricity service providers to estimate the DR potential dynamically before the DR event. In contrast with static models that estimate DR potential regardless of specific conditions of the event time (e.g. the next day), our proposed dynamic approach determines the DR potential by solving the relevant dispatch optimization problem, taking into account load and generation forecasting.

The contributions of this work are threefold:

1. Integrated System Architecture: This study integrates and automates different systems and communication architectures between electricity markets and building/microgrid customers, using internationally accepted open standards for DR and price communications. The proposed integrated system architecture enables dynamic model-in-the-loop simulations.

2. New Models for Electric Grid Transactions: This work develops new models for customer DER optimization and participation for common loads such as heating, cooling, and lighting systems, based on standardized utility DR signals.

3. Application of Models in a Case Study and Autonomous Operations: A real-world case study has been conducted based on the newly developed DR program participation models. 
Figure 1 below shows the typical existing DR and automation operation scenario compared to our proposed solution to enable customer-side DER participation in present and future electricity markets. In the current automated DR programs in California, the electricity service provider or the utility dispatches a DR event to the customer to activate a pre-estimated load change. Once the customer responds, the DR settlement or verification of the committed response is conducted ex-post. In this scenario, there is no information exchange if the customer can meet the pre-estimated load change until the ex-post analysis is conducted. The key innovation is the feedback of scheduled resources based on the model-in-the-loop simulations and optimizations, as well as the use of open standards for smart grid interoperability, which enables electricity service providers to better plan their electricity purchase for the forecasted demand and cost effective systems integration using DR resources.

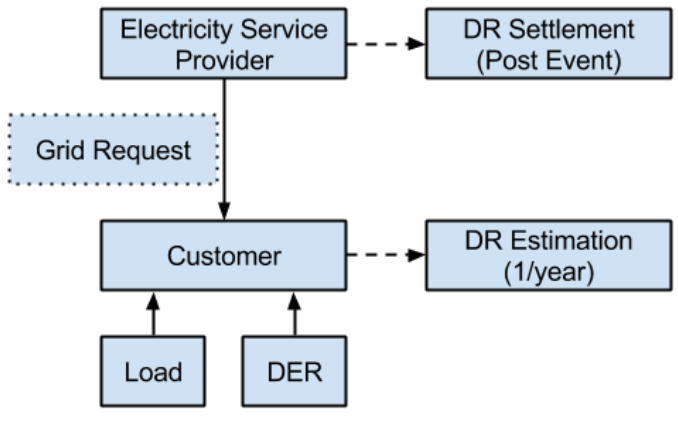

(a)

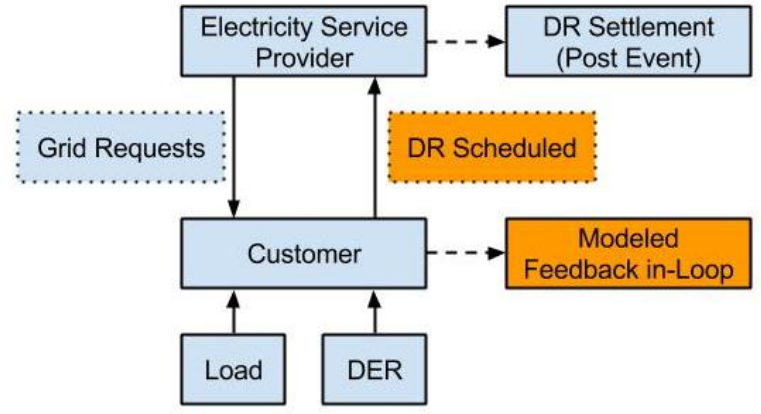

(b)

Figure 1: (a) Existing grid transaction operation scenario, and (b) new dynamic operation scheme for DER (right)

We use linear optimization techniques, open standards, and optimization models for resource planning to propose new models and feedback mechanisms based on notifications from the electric grid. This solution empowers DR and electricity service providers with reliable ex-ante information on customers' load flexibility due to on-site DER.

This work demonstrates technologies that enable optimized cost and energy choices for customer-side DER for select automated DR (AutoDR) programs that are deployed by the utilities:

- For DR signals we use the open standard OpenADR, which is used by California utilities for AutoDR programs. We chose AutoDR because it does not involve human intervention, but is initiated at a customer site (e.g., building) through the receipt of external communication signals [8], which is necessary to address faster response times. Automation is needed for the dynamic interactions between customers and next-generation grid and for a faster customer response.

- For optimization of dynamic model-in-the-loop, we use the integrated system tool DER-CAM (distributed energy resources customer adoption model). DER-CAM is a state-of-the-art design support tool for microgrids, as well as an optimization engine for microgrid controllers.

- $\quad$ To determine customers' DR capabilities we used the DR quick assessment tool (DRQAT).

DER-CAM and DRQAT are used in a closed-loop optimization setup to assess the effectiveness and feasibility for customer-side DER participation in DR programs and grid transactions. We applied the integrated architecture and developed models to a real-world test site: Fort Hunter Liggett, an army base in California with various DER technologies. For this site we considered day-ahead DR market signals for peak-day pricing (PDP), critical-peak pricing (CPP), and real-time pricing (RTP). While all these programs are based on the utility dispatch for DR, the PDP and CPP programs are based on electricity rate tariffs and RTP provides hourly values of electricity price, all in $\$ / \mathrm{kWh}$ or $\$ / \mathrm{MWh}$ formats. We considered the day-ahead scenarios and not fast response needs such as ancillary 
services (spinning and non-spinning reserve) wholesale DR markets as the DER-CAM and DRQAT optimization is not developed to address these needs at this point. This is subject to further research. The tests and simulation runs were conducted to generate feedback for load flexibility, load profiles, and DR participation schedules, which both electricity service providers and customers can use for resiliency and reliability. For our models, we use day-ahead planning and operation for DR and the data exchange between the utility and the facility is done once a day. DERCAM conducts the analysis locally and the utility is notified of the facility operation and DR availability in 15-minute intervals for the next day. This data exchange is similar to the practice that the utilities widely use to monitor daily energy use.

The transactive energy elements are considered to optimize the DER to identify and provide load flexibility for energy markets. The specific objectives of this work are to:

- optimize DER based on electric grid signals to allow customers to participate in grid transactions,

- demonstrate optimized sequences and technologies for customer-side DER, such as natural/biogas-fired combined heat and power (CHP), batteries/storage, photovoltaic (PV), heat storage, etc., and

- generate DER availability and feedback via AutoDR to grid operators and to DER participation in electricity markets.

This paper is organized into the following sections:

- Section 2 describes the tools used in the study and explains the architectural contribution of this work, in integrating them for dynamic demand response.

- Section 3 describes the modeling contribution of this work.

- Section 4 describes the case studies and their setup, as well as assumptions; it also discusses the results.

- Section 5 describes the conclusions and future work.

\section{Systems Integration, Technology Resources}

To better understand the smart grid domains and the system integrations in our study, we provide the following framework of macro- and micro-level integration to optimize customer-side DER systems and loads for electricity grid transitions. Figure 2 shows the four generic domains of the smart grid and their associated energy systems: namely, generation, transmission, distribution, and customers (microgrids and end-use systems). It is important to note the shift of traditional centralized power generation and consumption using one-way power systems. In the new paradigm of DG, the generation systems produce power within all domains, and hence must support two-way power and energy flows, interconnection requirements, and optimization necessary to balance the electric grid of the future. This study focuses on the systems integration within the three domains shown in the shaded part and power-related information exchange within them, as shown by the arrows (arrows between the DG, transmission, and distribution systems are not shown in the figure, to highlight the customer-centric focus of the study). The optimization focuses on enabling the customer's DER for grid transactions for the electricity service providers and systems operators. The impacts of customers' energy use are realized across all the four smart grid domains.

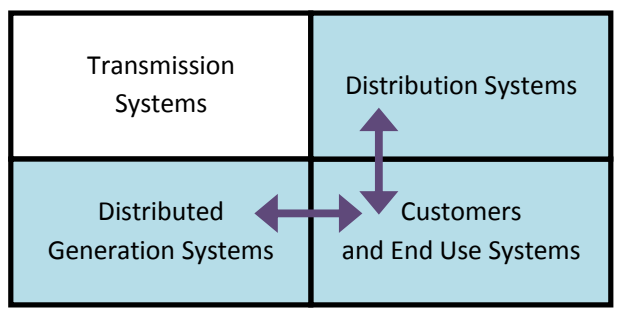

Figure 2: Smart grid domains, energy systems integration, and optimization framework 
For this study we used existing technologies and tools to develop models that integrate DER with electric grid transactions and to enable customer participation in DR programs. These technologies are DER-CAM, DRQAT, and Open Automated DR (OpenADR) communication standards, which are all briefly introduced in the following subsections. The OpenADR standard, which defines the data for different DR programs and adopted by most of the utilities in the United States, is used to provide data models for PDP, CPP, and RTP. An OpenADR client was developed in DER-CAM to get the DR information from the utilities. The DER-CAM tool has been modified within this work to reflect the impact of dynamic grid pricing.

\subsection{The Distributed Energy Resource Customer Adoption Model}

Many formulations in the energy systems aim to address the optimal operation-scheduling problem in microgrids (customers in Figure 2). Microgrids are "electricity distribution systems downstream of a utility substation containing loads and DER (such as distributed generators, storage devices, or controllable loads) that can be operated in a controlled, coordinated way, either while connected to the main power network or while islanded" [9]. Depending on the types of energy systems included in the problem, these formulations can be classified into two groups. Some of these algorithms only focus on electrical energy flow and neglect the thermal energy flow, e.g., [10-22]. However, in microgrids, optimal dispatch of thermal resources is as important as electrical resources, and simultaneous optimization of thermal and electrical resources is of great importance, especially when the two are linked through CHP-enabled technologies [23]. Some of the formulations that integrate thermal and electrical energy systems are presented in [24-27].

As for the type of optimization problem and solution methodology, two approaches are used in the literature. Some formulations simplify the modeling so that the problem can be formulated as a linear or a convex optimization problem, e.g., $[12,17,23,25$, 26]. Others formulate a nonlinear optimization problem, e.g., [10, 11, $13-16,18,19,21,22,24,27,28]$ and provide heuristic solutions to the non-convex problem, e.g., teachinglearning-based optimization [28], multi-agent optimization [10], multi-objective mesh adaptive direct search [14], quantum evolutionary algorithm [15], or particle swarm optimization [27]. The advantage of linear formulations lies in their scalability and guarantee of finding the optimum solution. On the other hand, the nonlinear approaches may contain more detail about the models and may be more accurate.

For the work presented in this paper, an optimal operation-scheduling model for buildings and microgrids called DER-CAM was adapted. DER-CAM is a flexible decision-support tool for decentralized integrated energy systems, and has two major versions: Investment \& Planning DER-CAM and Operations DER-CAM (please find more details in Appendix A). Operations DER-CAM, which is the version adapted and used in this work, has been previously applied to a diverse number of applications, including day-ahead scheduling of battery storage at the Santa Rita Jail microgrid $[29,30]$ and automated day-ahead scheduling of thermal resources at a University of New Mexico campus building $[23,31]$.

\subsection{Demand Response Quick Assessment Tool}

Predicting building performance and user reactions under dynamic conditions such as DR events, or evaluating the effects of energy-saving strategies and comfort, can be a challenge for simulation models. Several studies have looked at modeling these types of dynamic control strategies for building systems. Reference [32] studies the application of DR simulation models in commercial buildings and develops a data-driven-based dynamic model to simulate the effect of different thermostat control strategies to reduce peak demand. Reference [33] investigates two optimal dynamic building control strategies in a representative room in a large office building. Reference [34] shows the potential for reducing peak electrical demand in moderate-sized commercial buildings by modifying heating, ventilation and air conditioning (HVAC) system control. Peak-load reduction strategy modeling studies by 
Yin et al. [35] developed and calibrated simulation models of 11 commercial buildings for evaluating the effect of different thermostat control strategies.

The Demand Response Quick Assessment Tool (DRQAT) is another tool for this application, and is used to develop models for simulating various DR strategies to estimate the demand shedding and shifting potential [35]. DRQAT is based on the modeling engine and capabilities of EnergyPlus [36]. As input, DRQAT receives basic building information such as building type, area, technologies and systems, orientation, utility tariffs, etc. The building models in DRQAT use the prototypical simulation models to calculate energy and demand-reduction potential under certain DR strategies, such as pre-cooling, zone temperature set-point adjustment, chilled water loop and air loop set-point adjustment, and light dimming or on/off. Appendix B presents the summary of DR strategies in field test case studies [37]. Typical DR control strategies, such as global temperature adjustment, dimming or turning on/off lights, and turning on/off unnecessary plug load will be simulated by using DQRAT to evaluate the load shed potential for each building type.

\subsection{Open Automated Demand Response Standards}

Open Automated Demand Response (OpenADR) is a U.S. smart grid interoperability standard to facilitate secure and cost-effective communication of electricity price and system grid reliability signals, allowing automated facility responses. OpenADR provides non-proprietary interfaces to enable the electric grid to communicate DR and DER signals to customers using a common language and existing communications [8]. A Virtual Top Node (VTN) and a Virtual End Node (VEN) are two major components in the interface of an OpenADR server, which allows hierarchy among the parent (VEN or the one that issues the primary DR signal) to the multiple parent/child relationships all the way to the customers (VEN or the one who receive and respond to grid signals.) [38]. OpenADR-based Automated DR (AutoDR) programs have been offered by the California utilities since 2007 and are integrated with over 1,200 customer systems to provide over $250 \mathrm{MW}$ of AutoDR [5]. OpenADR is used as a signaling infrastructure for DR transactions at different timescales and system integration levels within an electric grid [39]. OpenADRbased systems are also being used for grid-based transactions [40]. Appendix C describes OpenADR in more details.

\subsection{Distributed Energy Resource Optimization and Demand Response Integration}

Figure 3 shows the closed-loop interactions between a utility and a customer whose DER operation schedules are determined by DER-CAM. The utility places the day-ahead OpenADR demand response signal on the OpenADR server. This signal contains the day-ahead RTP or PDP program information, and the OpenADR client (i.e., the customer) reads the signal from the server. The DR program information is passed on DER-CAM in our case. Other dynamic inputs to the customer's DER-CAM are the weather, renewable generation, and load forecasts. After receiving all the required input, DER-CAM minimizes the operation costs (or carbon dioxide emission) and determines the optimum operation schedules for the DERs and loads for the next day. The operation schedules are conveyed to an Energy Management and Controls System (EMCS) to change operations. A subset of the building's operation schedules is sent to the OpenADR server and channeled to the DR service provider. 


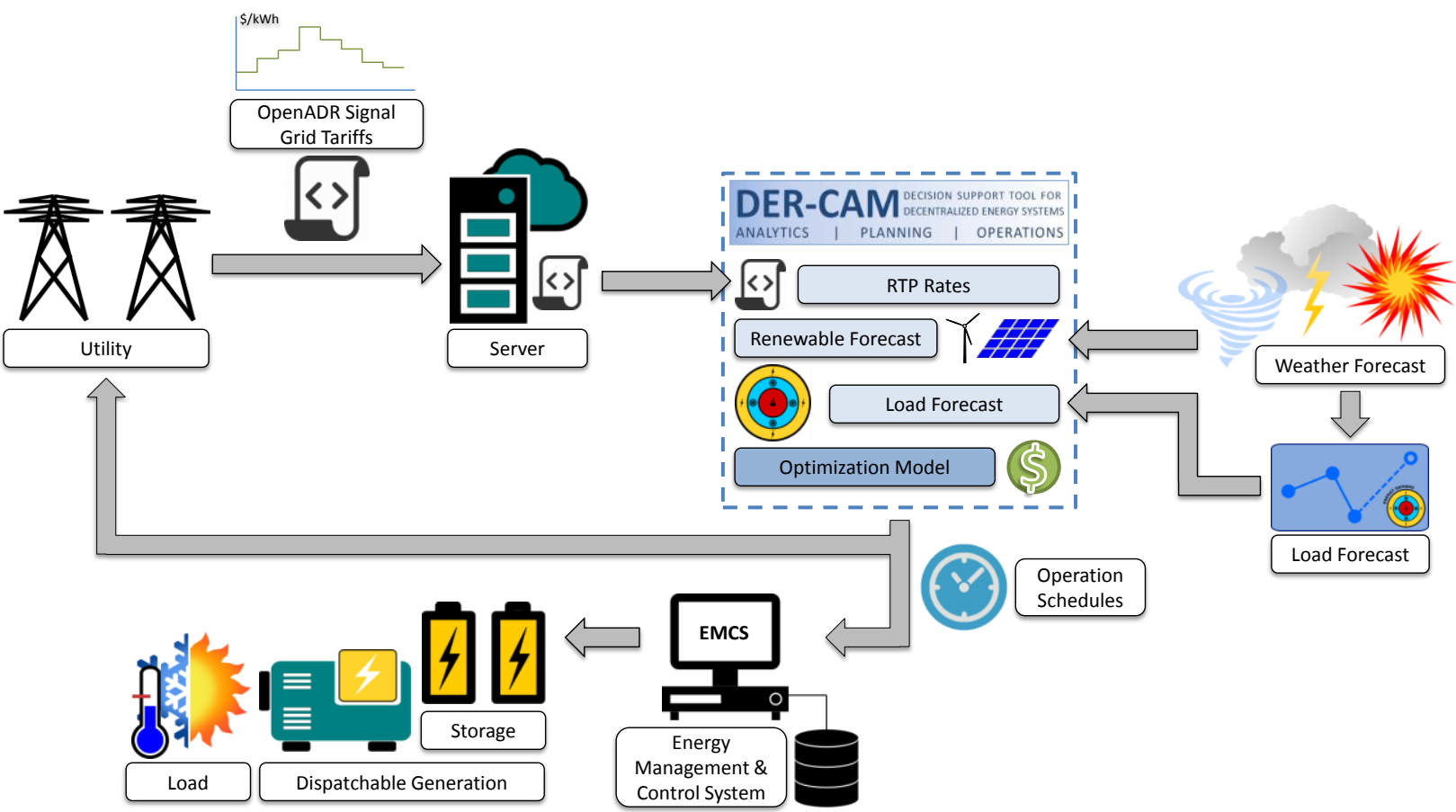

Figure 3: Schematic diagram of the closed-loop interactions between a DR service provider and a DER-CAM-enabled customer

The microgrid's demand response potential is among the inputs for DER-CAM. To identify a microgrid's DR potential we used DRQAT for a kilowatt-shed estimation. As shown in Figure 4, each level of the load change potential was estimated using DRQAT and was used as an input to DER-CAM. The key DRQAT inputs include building information and location, internal loads, energy technologies, etc. The key DRQAT outputs include load profiles and DR potential that can be achieved. We use OpenADR as a standardized communication technology to notify the customer of DR requests, to plan responses, and notify the DR service provider on the estimated potential before the DR event.

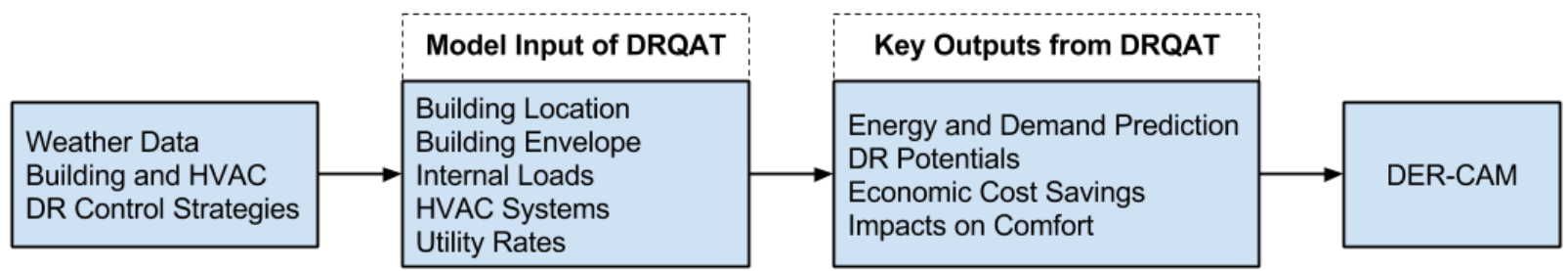

Figure 4: Kilowatt shed potential from DRQAT to DER-CAM

The project team set up an OpenADR client and server for tests and DER integration by providing electric grid signals between the VTN and the VEN. Figure 4 shows the communications and information exchange between the OpenADR VTN to the OpenADR VEN, which is integrated with DER-CAM at the customer or microgrid level. The system is compatible with OpenADR $2.0 \mathrm{a}$ and $2.0 \mathrm{~b}$ data profiles. In this study we created a client for DER-CAM to request the OpenADR signal from the OpenADR server. On the server side we created an event for each DR program. Under each program, the OpenADR signal includes signal type (e.g., price, level, and set-point), time (start, end, and duration), current value, and signal ID. 


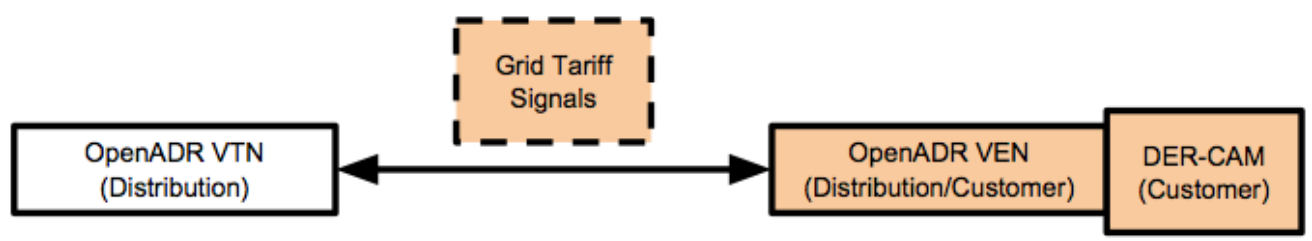

Figure 5: The OpenADR Communication Architecture and DER-CAM Integration

\section{Demand Response Modeling and Distributed Energy Resources Optimization}

DRQAT and DER-CAM form central pieces of this study to integrate energy systems and optimize customer DR and DER. To help the readers understand the modeling approach in this work, the basic DRQAT modeling method is explained in Section 3.1. Then, Section 3.2 presents the DER-CAM optimization model. To address the special requirements for demand response programs the DER-CAM model has been enhanced, as discussed in Sections 3.2.1 and 3.2.2.

In this work, we focus on two types of day-ahead DR programs: Real-Time Pricing (RTP) [41-43] and Peak Day Pricing (PDP) [44] programs, which are offered by California utilities to their large commercial and industrial customers. While PDP is a dynamic pricing-based day-ahead DR program, a RTP program provides pricing schedules that are based on the prior day's temperature. The PDP program has a high price period from 2 pm to $6 \mathrm{pm}$, with a typical 9 to 15 PDP events per year, which are triggered during the hot summer days. A variant of the PDP program is the Critical Peak Pricing (CPP) program [44], which is defined by a six-hour high price period from $12 \mathrm{pm}$ to $6 \mathrm{pm}$.

\subsection{DRQAT Model}

The DRQAT model, which is based on EnergyPlus model, uses a simulation approach to solve the differential equations for the zones and air systems integration. In addition to the load reduction of lighting and plug loads, the global temperature set-point adjustment contributes to the cooling load reduction. By solving the integral equation between the zone and air system in the model, the reduced airflow of the air system will lead to the fan power reduction on the air-side system and the power reduction of the plant side components (e.g., chiller, pumps, cooling towers). Based on the previous experience of DR implementation in commercial buildings, three categories of DR strategies were selected in this case study: (1) global temperature set-point adjustment; (2) dimming the lights, and (3) turning off unnecessary plug loads. The aggregated potential of load reduction will be used as maximum demand response potential in DER-CAM.

A comprehensive parametric analysis was conducted to discover the load shedding and shifting potential at different levels by adjusting system variables for DR control. In a variable-air-volume HVAC system, the change in the zone temperature set points alters the air mass flow within the norms. The model was developed in DRQAT to quantify the impact of the change of DR control parameters on the load shed at the whole-building level. For each category of DR control strategy, three levels of the load shed potential were identified: low, medium, and high. For example, the $\Delta T_{\text {setpoint }}$ of the HVAC control strategy was given at three levels: $2^{\circ} \mathrm{F}, 4^{\circ} \mathrm{F}$, and $6^{\circ} \mathrm{F}$ above the regular set point of $72^{\circ} \mathrm{F}$. In particular, the acceptable comfort range of temperature set points was defined from $68^{\circ} \mathrm{F}$ to $78^{\circ} \mathrm{F}$. In summary, we developed a simulation matrix of different parameters for each control strategy to quantify the load shed potential of each service level as shown in equation (1) where $\Delta T_{\text {setpoint }}$ is the temperature setpoint adjustment and $2 \leq \Delta T_{\text {setpoint }} \leq 6 ; \Delta P_{\text {lights }}$ is the load change potential by dimming or turning off lights; $\Delta P_{\text {plug }}$ is load change potential for plug loads, $\triangle P_{H V A C}$ is the load shed potential from building HVAC systems when implementing the DR control strategies of adjusting temperature setpoints. $\Delta P_{H V A C}$ also depends on $\Delta P_{\text {lights }}$ and $\Delta P_{\text {plug. }} \Delta P_{\text {building }}$ is the aggregated demand response potential of the building. 


$$
\Delta P_{\text {building }}=\Delta P_{H V A C}\left(\Delta T_{\text {setpoint }}, \Delta P_{\text {lights }}, \Delta P_{\text {plug }}\right)+\Delta P_{\text {lights }}+\Delta P_{\text {plug }}
$$

\subsection{DER-CAM Optimization Model}

To simplify the equations and enhance the readability of the DER-CAM optimization model, it is assumed that the optimization time step is one hour and that the optimization horizon is one day.

\section{Sets and Indices}

C

g

$\mathrm{k}$

j

i

$\mathrm{t}$

u

e

$\mathrm{p}$

$\mathrm{q}_{\mathrm{p}}$

r

\section{Customer loads}

Cload $_{\mathrm{u}, \mathrm{t}}$

\section{Market data}

CTax

CDRLoadMax $_{\mathrm{r}, \mathrm{u}}$

DRPrice $_{\mathrm{r}, \mathrm{u}}$

MktMCRate $_{\mathrm{t}}$

NGCRate $_{j}$

NGPrice

RTEExport $_{t}$

RTEnergy $_{t}$

RTPower $_{p}$

\section{RTP and PDP data}

RTPMaxCost

RTPRate $_{t}$

DeltaUtilPur

UtilPurBaseline $_{\mathrm{t}}$

\section{Technology data}

$\mathrm{COP}_{\mathrm{c}}$

DERmaxp $_{\mathrm{g}}$

DEROMvar $_{i}$ set of continuous (available in every size) generation technologies: photovoltaics (PV), solar thermals (ST), absorption chillers (AC), electric chillers (EC), absorption refrigerators (AR), electric refrigerators (ER)

set of discrete generation (only available in discrete sizes) technologies: internal combustion engines (ICE), micro-turbines (MT), gas turbines (GT), fuel cells (FC). Note: more info the difference between discrete and continues technologies can be found at [45].

set of continues storage technologies: electric storage (ES), heating storage (HS), cooling storage (CS)

set of all generation technologies: $\mathrm{g} \cup \mathrm{c}$

set of all technologies: $\mathrm{j} \cup \mathrm{k}$

set of time steps: $1,2, \ldots, T$

set of end-uses: electricity only (eo), cooling (cl), refrigeration (rf), space heating (sh), water heating (wh), natural gas only (ng)

set of energy types for energy balance equations: electricity (el), heating (ht), cooling (cl), refrigeration ( $\mathrm{rf}$ )

set of demand charge periods (relates to electric tariffs and rates): on-peak, mid-peak, offpeak, coincidental, non-coincidental

set of all time steps $\left(q_{p} \subset \mathrm{t}\right)$ that fall in the demand charge period $p$

set of demand response types: low, med, high

customer load in time t for end-use $\mathrm{u}, \mathrm{kW}$

tax on carbon emissions, $\$ / \mathrm{kg}$

demand response potential for enduse $u$ and demand response type $r$

cost of demand response measure of type $r$ and end-use $u, \$ / k W h$

marginal carbon emissions from marketplace generation (e.g., utility) in time $\mathrm{t}, \mathrm{kg} / \mathrm{kWh}$

$\mathrm{CO}_{2}$ emissions rate from generation technology $\mathrm{j}, \mathrm{kg} / \mathrm{kWh}$

price of natural gas, $\$ / \mathrm{kWh}$

regulated tariff for electricity export in time $t, \$ / k W h$

regulated tariff for electricity purchase in time $\mathrm{t}, \$ / \mathrm{kWh}$

regulated demand charge under the default tariff for period $p, \$ / k W$

maximum desirable daily energy cost in RTP program, $\$$

real-time pricing rate for time $\mathrm{t}, \$ / \mathrm{kWh}$

requested change in the customer's utility electricity consumption compared to the baseline in PDP program, kWh

customer's utility electricity consumption baseline at time $\mathrm{t}$ in PDP program, $\mathrm{kWh}$

coefficient of performance for technology $c$ (chillers and refrigerators)

nameplate power rating of discrete generation technology $\mathrm{g}$, kW

variable operation and maintenance costs of technology $i, \$ / k W h$ 


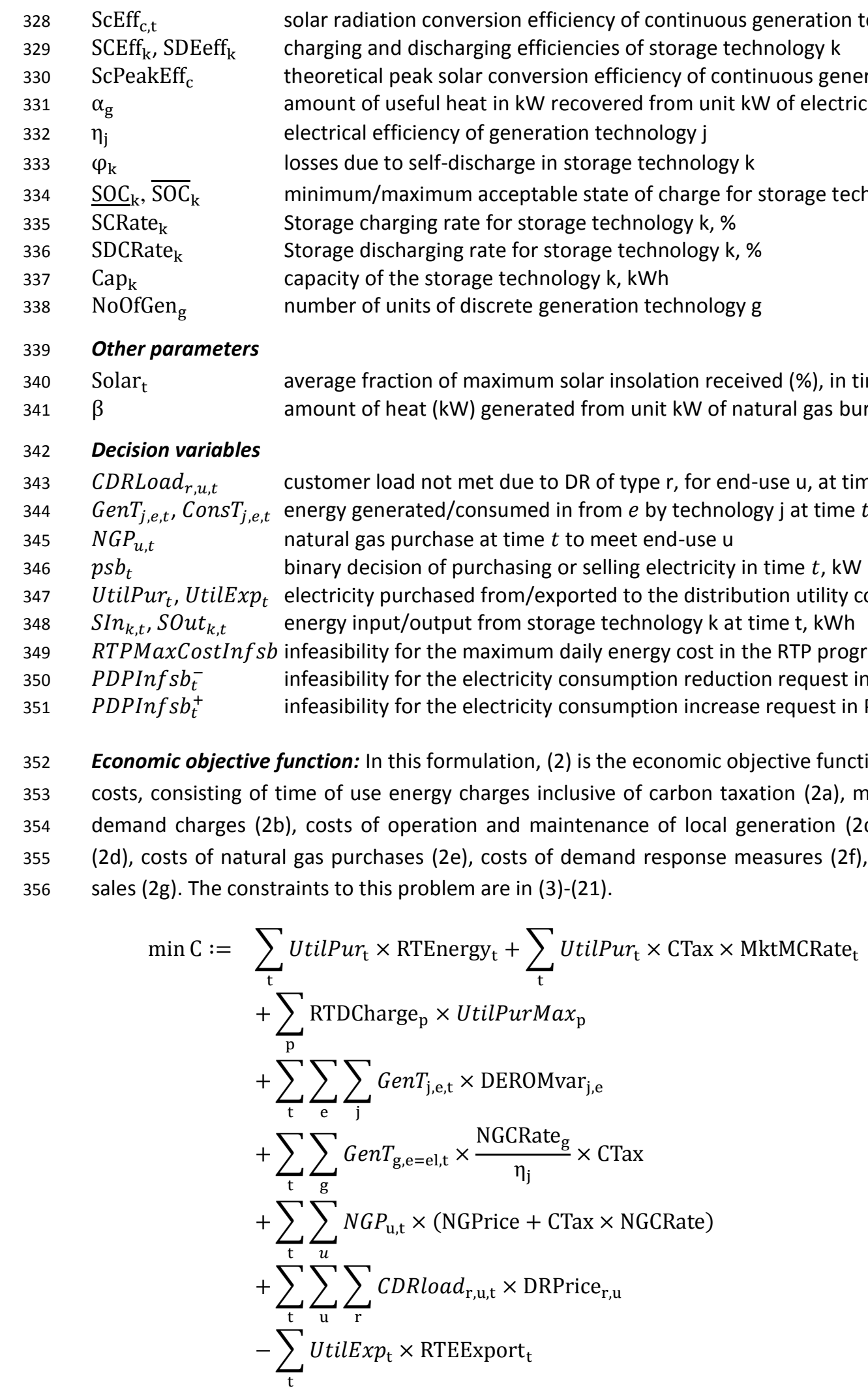


Energy balance constraints: Equations (3)-(7) enforce energy balance for different end uses. For instance, (3) states that electricity loads, minus the load not met due to demand response measures, plus the electricity consumption of technologies (e.g., electric chiller or refrigerator), plus the electricity for charging storage technologies, plus the electricity exported to the grid must equal the electricity generated by local generators, plus the electricity purchased, plus the electricity from storage technologies (charging and discharging cannot occur simultaneously). Similarly, (4) is for heat balance (space heating and water heating loads) and also considers the heat recovery from CHP units and absorption chillers which can run on waste heat. Equations (5)-(7) are for cooling, refrigeration, and natural-gas loads, respectively.

$$
\begin{aligned}
& \operatorname{Cload}_{\mathrm{u}, \mathrm{t}}-\sum_{\mathrm{r}} \operatorname{CDRload}_{\mathrm{r}, \mathrm{u}, \mathrm{t}}+\sum_{\mathrm{j}} \operatorname{ConsT}_{\mathrm{j}, \mathrm{e}, \mathrm{t}}+\frac{\operatorname{SInput}_{\mathrm{k}, \mathrm{t}}}{\operatorname{SCEff}_{\mathrm{k}}}+\operatorname{UtilExp}_{t} \\
& =\sum_{\mathrm{j}} \operatorname{GenT}_{\mathrm{j}, \mathrm{e}, \mathrm{t}}+\text { UtilPur }_{\mathrm{t}}+\text { SOut }_{\mathrm{k}, \mathrm{t}} \times \operatorname{SDEff}_{\mathrm{k}} \quad \forall \mathrm{t}: \mathrm{u} \in\{\mathrm{eo}\}, \mathrm{e} \in\{\mathrm{el}\}, \mathrm{k} \in\{\mathrm{ES}\} \\
& \sum_{\mathrm{u} \in\{\text { sh,wh }\}}\left(\operatorname{Cload}_{\mathrm{u}, \mathrm{t}}-\sum_{r} \operatorname{CDRload}_{\mathrm{r}, \mathrm{u}, \mathrm{t}}\right)+\sum_{\mathrm{j}} \operatorname{ConsT}_{\mathrm{j}, \mathrm{e}, \mathrm{t}}+\frac{\operatorname{SIn}_{\mathrm{k}, \mathrm{t}}}{\operatorname{SCEff}_{\mathrm{k}}} \\
& =\sum_{\mathrm{j}} \operatorname{GenT}_{\mathrm{j}, \mathrm{e}, \mathrm{t}}+\operatorname{SOut}_{\mathrm{k}, \mathrm{t}} \times \operatorname{SDEff}_{\mathrm{k}}+\sum_{\mathrm{u} \in\{\mathrm{sh}, \mathrm{wh}\}} \beta \times N G P_{\mathrm{u}, \mathrm{t}} \quad \forall \mathrm{t}: \mathrm{e} \in\{\mathrm{ht}\}, \mathrm{k} \in\{\mathrm{HS}\} \\
& \operatorname{Cload}_{\mathrm{u}, \mathrm{t}}+\frac{\operatorname{SIn}_{\mathrm{k}, \mathrm{t}}}{\operatorname{SCEff}_{\mathrm{k}}}=\sum_{\mathrm{j}} \operatorname{GenT}_{\mathrm{j}, \mathrm{e}, \mathrm{t}}+\operatorname{SOut}_{\mathrm{k}, \mathrm{t}} \times \operatorname{SDEff}_{\mathrm{k}} \quad \forall \mathrm{t}: \mathrm{u} \in\{\mathrm{cl}\}, \mathrm{e}=\{\mathrm{cl}\}, \mathrm{k} \in\{\mathrm{CS}\} \\
& \operatorname{Cload}_{\mathrm{u}, \mathrm{t}}=\sum_{\mathrm{j}} \operatorname{GenT}_{\mathrm{j}, \mathrm{e}, \mathrm{t}} \quad \forall \mathrm{t}: \mathrm{u} \in\{\mathrm{rf}\}, \mathrm{e}=\{\mathrm{rf}\} \\
& \text { Cload }_{\mathrm{u}, \mathrm{t}}=N G P_{\mathrm{u}, \mathrm{t}} \quad \forall \mathrm{t:} \mathrm{u} \in\{\mathrm{ng}\}
\end{aligned}
$$

Limit on simultaneous electricity purchase and sell: Equations (8) and (9) ensure that electricity cannot be purchased and sold simultaneously, using a binary variable. In these equations, $\mathbf{M}$ is an arbitrary large quantity.

$$
\begin{array}{cr}
\operatorname{UtilPur}_{\mathrm{t}} \leq p s b_{\mathrm{t}} \times \mathbf{M} & \forall \mathrm{t} \\
\operatorname{UtilExp}_{\mathrm{t}} \leq\left(1-p s b_{\mathrm{t}}\right) \times \mathbf{M} & \forall \mathrm{t}
\end{array}
$$

On-site generation limits: Equation (10) enforces the on-site generating capacity constraint by stating that the energy generated is limited to the installed capacity. Equation (11) constrains solar conversion technologies to generate in proportion to the solar insolation and conversion efficiency.

$$
\begin{gathered}
\operatorname{GenT}_{\mathrm{g}, \mathrm{e}, \mathrm{t}} \leq \text { NoOfTech }_{\mathrm{g}} \times \text { DERmaxp }_{\mathrm{g}, \mathrm{e}} \quad \forall \mathrm{g}, \mathrm{e}, \mathrm{t} \\
\operatorname{GenT}_{\mathrm{c}, \mathrm{e}, \mathrm{t}} \leq \operatorname{Cap}_{\mathrm{c}} \times \frac{\text { ScEff }_{\mathrm{c}, \mathrm{t}}}{\operatorname{ScPeakEff}_{\mathrm{c}}} \times \text { Solar }_{\mathrm{t}} \quad \forall \mathrm{t}, \mathrm{c}: \in\{\mathrm{PV}, \mathrm{ST}\}, e \in\{\mathrm{ht}\}
\end{gathered}
$$

Storage balance and limitations: Equation (12) enforces energy balance in storage technologies, (13) forces the state of charge to be within the acceptable range, and (14) and (15) place a limit on charging and discharging rates.

$$
\begin{gathered}
S O C_{k, t}=\left(1-\varphi_{\mathrm{k}}\right) \times S O C_{k, t-1}+\operatorname{SIn}_{k, t}-\operatorname{SOut}_{k, t} \forall \mathrm{t}, \mathrm{k} \\
\underline{\operatorname{SOC}}_{\mathrm{k}} \leq S O C_{\mathrm{k}, \mathrm{t}} \leq \overline{\operatorname{SOC}}_{\mathrm{k}} \\
\operatorname{SIn}_{\mathrm{k}, \mathrm{t}} \leq \operatorname{Cap}_{\mathrm{k}} \times \operatorname{SCRate}_{\mathrm{k}} \quad \forall \mathrm{k}, \mathrm{t} \\
\operatorname{SOut}_{\mathrm{k}, \mathrm{t}} \leq \operatorname{Cap}_{\mathrm{k}} \times \text { SDCRate }_{\mathrm{k}} \quad \forall \mathrm{k}, \mathrm{t}
\end{gathered}
$$


Limit on demand response: Equation (16) limits the amount of load reduction at each time step to the maximum potential. Note that the CDRLoadMax $r$,u's in this work are determined by the DRQAT, as discussed in Section 3.1 .

$$
\text { CDRLoad }_{r, u, t} \leq \text { CDRLoadMax }_{\mathrm{r}, \mathrm{u}} \quad \forall \mathrm{r}, \mathrm{u}
$$

Heat recovery: Equation (17) determines how much heat can be recovered from CHP-enabled DER technologies.

$$
\operatorname{GenT}_{g, e_{1}, t} \leq \alpha_{\mathrm{g}} \times \operatorname{GenT}_{g, e_{2}, t} \quad \forall \mathrm{g}, \mathrm{t}: \mathrm{e}_{1} \in\{\mathrm{ht}\}, \mathrm{e}_{2} \in\{\mathrm{el}\}
$$

Consumption of cooling technologies: Equations (18) and (19) determine the relationship between electrical consumption and cooling and refrigeration generation for electrical chillers and refrigerators, respectively. Similarly, equations (20) and (21) determine the relationship between heating consumption and cooling and refrigeration generation for absorption chillers and refrigerators, respectively.

$$
\begin{array}{ll}
\operatorname{GenT}_{c, e_{1}, t}=\operatorname{Cons}_{c, e_{2}, t} \times \mathrm{COP}_{c} & \forall \mathrm{t}: \mathrm{c} \in\{\mathrm{EC}\}, \mathrm{e}_{1} \in\{\mathrm{cl}\}, \mathrm{e}_{2} \in\{\mathrm{el}\} \\
\operatorname{GenT}_{c, e_{1}, t}=\operatorname{Cons}_{c, e_{2}, t} \times \mathrm{COP}_{c} & \forall \mathrm{t}: \mathrm{c} \in\{\mathrm{ER}\}, \mathrm{e}_{1} \in\{\mathrm{rf}\}, \mathrm{e}_{2} \in\{\mathrm{el}\} \\
\operatorname{GenT}_{c, e_{1}, t}=\operatorname{Cons}_{c, e_{2}, t} \times \mathrm{COP}_{c} & \forall \mathrm{t}: \mathrm{c} \in\{\mathrm{AC}\}, \mathrm{e}_{1} \in\{\mathrm{cl}\}, \mathrm{e}_{2} \in\{\mathrm{ht}\} \\
\operatorname{GenT}_{c, e_{1}, t}=\operatorname{Cons}_{c, e_{2}, t} \times \mathrm{COP}_{c} & \forall \mathrm{t}: \mathrm{c} \in\{\mathrm{AR}\}, \mathrm{e}_{1} \in\{\mathrm{rf}\}, \mathrm{e}_{2} \in\{\mathrm{ht}\}
\end{array}
$$

\subsubsection{Model for Real-Time Pricing}

For RTP-based operations a new constraint was added to DER-CAM, which enables the customer to set a maximum daily energy cost constraint. The customer can use this enhancement to limit its energy costs during high-price days, granted its willingness to reduce some loads (time and amount of load reduction is decided by DER-CAM). Another cost-limitation strategy could be to set a maximum yearly cost. The maximum daily energy cost constraint can be shown as (22), in which the energy rates at each time are the RTP rates, as shown in (23). In (22), RTPMaxCost is the maximum allowed daily energy cost for the customer, and RTPMaxCostInfsb is used to keep the problem feasible, if the goal cannot be achieved after shedding all possible loads. For this purpose, a new term, RTPMaxCostInfsb $\times \mathbf{M}$, is added to the optimization objective function, as shown in (25), in which $\mathbf{M}$ is an arbitrary large number. If the maximum daily energy cost constraint can be met by using local generation, local storage, load shifting, and load curtailment, then RTPMaxCostInf $s b$ will be zero. Otherwise, RTPMaxCostInf sb will be non-zero, and its values will be the extra energy cost above the set goal.

$$
\begin{gathered}
\sum_{\mathrm{t}} \text { UtilPur }_{\mathrm{t}} \times \text { RTEnergy }_{\mathrm{t}} \leq \mathrm{RTPMaxCost}^{\mathrm{R}}+\text { RTPMaxCostInfs } \\
\text { RTEnergy }_{\mathrm{t}}=\text { RTPRate }_{\mathrm{t}} \\
\text { RTPMaxCostInf } s b \geq 0
\end{gathered}
$$

new objective func $=$ original objective func in (3) + RTPMaxCostInfs $b \times \mathbf{M}$

\subsubsection{Model for Peak-Day Pricing}

In this work, we considered a variation of the existing PDP and CPP programs, in which the DR service provider sends a signal to the customer that includes the requested reduction/increase in the customer's utility electricity consumption during the next day's peak hours, e.g., 2 pm-6 pm. Although the PDP program is focused on loadreduction requests, a model for a load increase request was also considered in this work. A load increase request may be issued during over-generation periods. The requested reduction/increase cannot exceed the amount agreed upon in the PDP participation contract between the two parties. We assume that the customer is 
mandated to deliver the requested reduction/increase and will deliver the requested change, unless there are technical or capacity limitations. For this purpose, two new constraints were added to the Operations DER-CAM formulation. The new constraints for reduction and increase requests are shown in (26) and (28), respectively.

$$
\begin{array}{rr}
\text { UtilPur }_{t}-\text { PDPInfs }_{t}^{-} \leq \text {UtilPurBaseline }_{t}+\text { DeltaUtilPur, } & t \in\{\text { peak period }\}, \text { DeltaUtilPur }<0 \\
\text { PDPInfs } b_{t}^{-} \geq 0 & \\
\text { UtilPur }_{t}+\text { PDPInfs }_{t}^{+} \geq \text {UtilPurBaseline }_{t}+\text { DeltaUtilPur, } & t \in\{\text { peak period }\}, \text { DeltaUtilPur }>0 \\
\text { PDPInfs } b_{t}^{+} \geq 0 &
\end{array}
$$

In the above equations, UtilPurBaseline $e_{\mathrm{t}}$ is the baseline for the $t$-th time step, and $t \in$ \{peak period $\}$ shows the PDP event hours, i.e., $2 \mathrm{pm}-6 \mathrm{pm}$. The second term on the left-hand side of each equation, PDPInfs $b_{t}^{-}$or PDPInf $s b_{t}^{+}$, is used to keep the constraint feasible, even if it cannot be achieved after using all of the building resources for load reduction/increase. For this purpose, a new term has been added to the objective function, as shown in (30), in which $\mathbf{M}$ is an arbitrary big number.

$$
\begin{aligned}
\text { new objective func }= & \text { original objective func in (3) } \\
& +\sum_{t \in\{\text { peak period }\}}\left(P D P \operatorname{Inf} s b_{t}^{-}+P D P \operatorname{Inf} s b_{t}^{+}\right) \times \mathbf{M}
\end{aligned}
$$

In a decrease event if the requested reduction can be met by using available resources, then PDPInf $s b_{t}^{-1} s$ will be zero; otherwise PDPInfs $b_{t}^{-1} s$ will be non-zero and PDPInf $s b_{t}^{-}$will be the customer's deviation from the desired reduction at each time step. In an increase PDP event, i.e., DeltaUtilPur $>0$, if the requested increase can be met by using available resources, then PDPInf $s b_{t}^{+\prime} s$ will be zero. Otherwise, PDPInf $s b_{t}^{+ \text {'s }}$ will be non-zero and PDPInf $s b_{t}^{+}$will be the customer's deviation from the desired increase during the $t$-th time step.

The DER-CAM optimization model, presented in equations (2)-(21), is a Mixed Integer Linear Program (MILP). The new equations for RTP and PDP that were presented in (22)-(25) and (26)-(30), respectively, were also developed to exclude nonlinearities. Hence, the entire model including RTP and PDP equations is a MILP that can be solved quickly and efficiently with advanced MILP solvers, such as CPLEX, making it suitable for online or networked applications.

Regarding the dynamicity of the proposed model in the loop, it is worth clarifying that the load reduction potential for each load in the microgrid, which is determined using the DRQAT model, is a static input for the DER-CAM optimization. However, the microgrid's DR potential for the next day, observed from the point of common coupling, is dynamically determined by solving the DER-CAM optimization that takes into account load and generation forecast for the next day.

\section{Case Studies and Simulation Results}

\subsection{Test System - Fort Hunter Liggett}

For the case study, Fort Hunter Liggett (FHL) was chosen as the test energy system. The FHL site is the largest U.S. army reserve command post, covering about 162,000 acres in Monterey County, California [46]. There are about 250 permanent civilian and military residents in this facility. However, the population can rise to 4,000 during troop training. It has a peak electrical load of $2.4 \mathrm{MW}$ [46]. The site includes a system of $2 \mathrm{MW}$ of solar photovoltaics through four $500 \mathrm{~kW}$ inverters, 1 megawatt-hour (MWh) of lithium-ion (Li-ion) battery storage (2 units of $500 \mathrm{kWh} / 625 \mathrm{~kW}$ ), and several backup diesel generators, adding up to $4 \mathrm{MW}$. 
For FHL, load forecasts were produced using some available historical data from the site, along with some assumptions in terms of load shape. As an example, Figure 6 shows the load in kW electrical for six different end uses (electrical only, cooling, refrigeration, space heating, water heating, and natural gas only) and two-day types (non-peak weekdays and peak weekdays) in July. For PV forecasting, available PV generation measurements at a location less than $\mathbf{4 0}$ miles east of FHL were used. This information is available from the "Solar Power Data for Integration Studies" database developed by the National Renewable Energy Laboratory (NREL) [47].

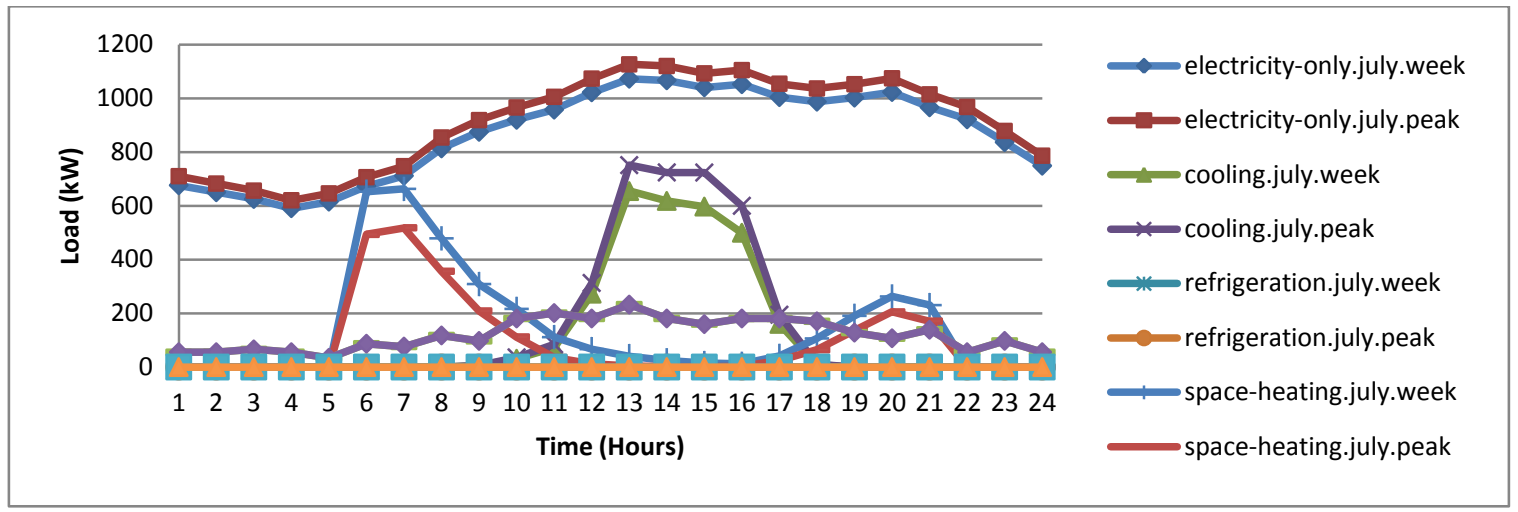

Figure 6: FHL loads for various end uses for some weekdays and peak days in July (LBNL estimates)

\subsection{Demand Response Programs}

In the case study we considered two demand response programs, i.e. RTP and PDP programs. For the setup of those two DR programs each pricing schedule is defined in VTN of the OpenADR server by creating each DR program event. For the RTP event setup 24 hours of price signals are defined in an event, based on the outside air temperature of the prior day. For the PDP event it is assumed that the signal includes the requested decrease/increase from the baseline consumption during the peak hours.

\subsection{Load Change Potential for Demand Flexibility}

DRQAT was used to simulate individual building energy and demand performance at FHL. The FHL site has 312 buildings with approximately 2 million square feet of building area, including administration, schools, family housing, barracks, industrial/motor pool, dining, recreation, and other facilities. The lodging, office, and warehouse buildings constitute the majority of building areas onsite [46]. Due to confidentiality issues we did not receive detailed building data (e.g., building information, HVAC system, and related control capabilities), and therefore, we assumed that each building type has the same load shed potential. The metric of DR shed percentage over the whole building (\%WBP) was used to scale up an individual building case to the entire facility site.

Using DRQAT to estimate the impact on load reduction during peak hours, three types of DR control strategies were evaluated (Table 1). For the "Global Temperature Adjustment" control strategy, three levels of temperature changes from the normal set point (e.g., $74^{\circ} \mathrm{F}$ ) were simulated to achieve 5 percent, 10 percent, and 15 percent load shed potential. For the DR control of the lighting it was assumed that lights in the daylight zone could be shut down completely and lights in the interior zones could be dimmed by one-third and two-thirds as the medium-and high-level DR. By aggregating a high-level load shed potential of each control strategy, 27 percent of the building demand can be shed.

Table 1: Summary of load-shed potentials for FHL

\begin{tabular}{|l|l|l|l|}
\hline DR Control Strategies & Levels & DR Controls & $\%$ reduction in WBP (Whole Building Power) \\
\hline
\end{tabular}




\begin{tabular}{|l|l|l|l|}
\hline \multirow{5}{*}{ Global Temp Adjustment } & Low & $2^{\circ} \mathrm{F}$ & $5 \%$ \\
\cline { 2 - 4 } & Medium & $4^{\circ} \mathrm{F}$ & $10 \%$ \\
\cline { 2 - 4 } & High & $6^{\circ} \mathrm{F}$ & $15 \%$ \\
\hline \multirow{3}{*}{ Lighting } & Low & Dimming & $2 \%$ \\
\cline { 2 - 4 } & Medium & Mixed & $6 \%$ \\
\cline { 2 - 4 } & High & Shut Down & $10 \%$ \\
\hline \multirow{3}{*}{ Other Types of Load } & Medium & Shut Down & $1 \%$ \\
\cline { 2 - 4 } & High & Shut Down & $2 \%$ \\
\hline
\end{tabular}

\subsection{Case Study One - Optimization of DER and DR Integration for Real-Time Pricing}

In the RTP program, the DR service provider uploads the RTP hourly prices for the next day to the OpenADR server. For this study we used SCE real-time price data, since Pacific Gas \& Electric does not offer a RTP program. The SCETOU-8 RTP values for 2-50 kV customers can be found in [42]. In this tariff structure, an energy charge of $\$ 0.02463 /$ kilowatt-hour $(\mathrm{kWh})$ is added to the hourly prices [41]. There is also a non-coincidental monthly demand charge of $\$ 14.88 / \mathrm{kW}$ for the customers. The prices are significantly different for different seasons/temperatures/days of the week, which provide great potential for optimization to reduce energy cost. As an example, Figure 7 compares the hourly prices between hot weather and extremely hot weather tariffs. In this tariff program, the temperature ranges for hot, very hot, and extremely hot weather are $85^{\circ} \mathrm{F}-90^{\circ} \mathrm{F}, 91^{\circ} \mathrm{F}-94^{\circ} \mathrm{F}$, and $>=95^{\circ} \mathrm{F}$, respectively [42].

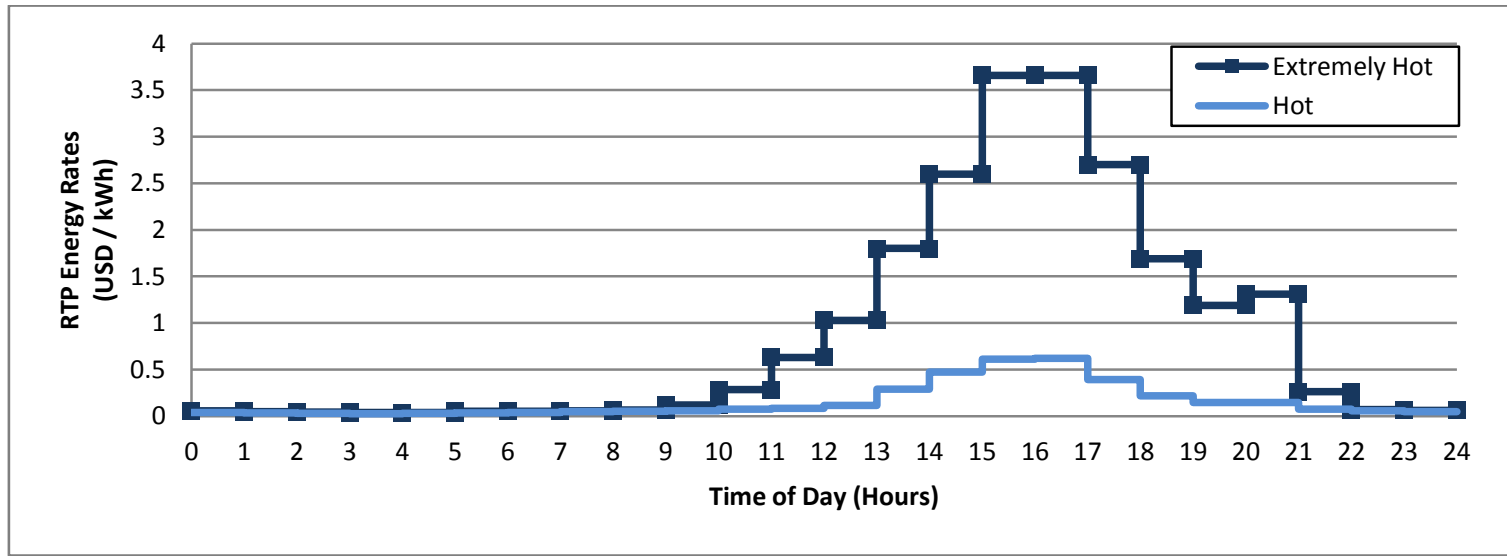

Figure 7: Comparison of RTP rates for extremely hot weather and hot weather (RTP program)

To simulate an RTP event, we took the following steps: (1) chose a date; (2) used values from NREL's database for PV generation forecast for the chosen date; (3) used load values from a peak day in the considered month as the load forecast; (4) set a maximum daily energy charge; (5) ran the DER-CAM optimization and analyzed the results. For the following analysis, load and PV values were chosen for a summer day in July. The customer's optimal dispatch was obtained, assuming three electric storage capacities of 1,000 kWh, 2,000 kWh, and 5,000 kWh, and for three types of weather temperatures: hot, very hot, and extremely hot.

To analyze the impact of the maximum daily energy cost constraint, i.e., equation (22), on the optimum day-ahead dispatch, we considered two sets of studies. In the first set, which is discussed in Section 4.4.1, the maximum daily energy cost constraint has been disabled, and in the second set, discussed in in Section 4.4.2, this constraint has been enabled. 


\subsubsection{Case Study without Daily Energy Cost Limit}

In the first set of studies, where results are summarized in Figure 8, the energy cost limit was disabled (i.e., RTPMaxCost in (22) was set to a large number). Consequently, since a very high penalty was set for load shedding, no load reduction was carried out. For each tariff type and each storage size, this figure shows daily electricity purchase, peak ( $2 \mathrm{pm}-6 \mathrm{pm}$ ) electricity purchase (during these hours the electricity is much more expensive), and daily energy cost (excluding demand charges). Results show that when a small battery (i.e., 1,000 or 2,000 kWh) is used, the customer's electricity purchase during 2 pm- 6 pm remains the same. Specifically, due to the lack of available resources the customer's energy consumption and battery charging/discharging strategy remains almost the same during the entire day, as shown in Figure 9. This means that customers do not have resource flexibility, and hence, the optimal strategy remains the same regardless of the electricity prices.

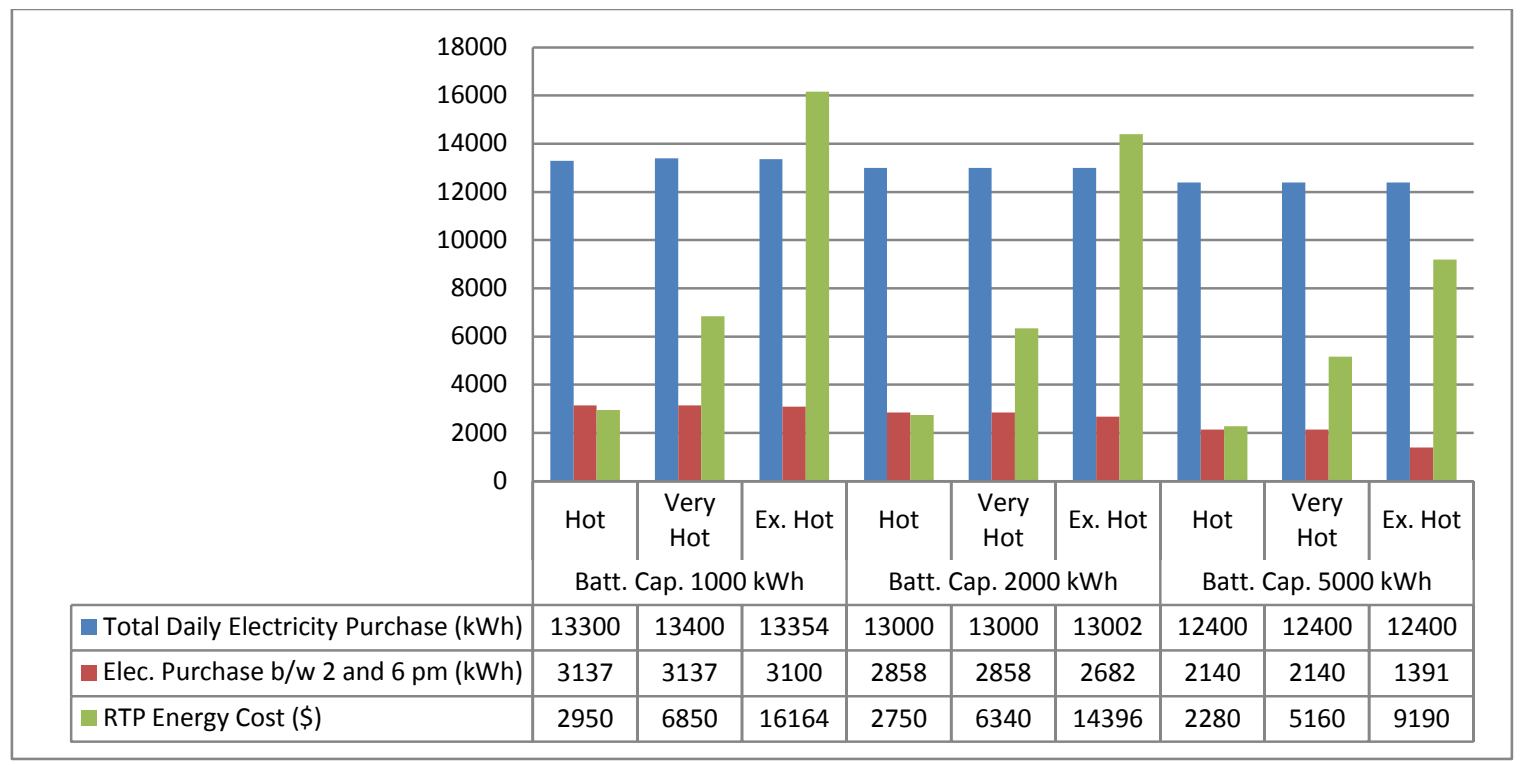

Figure 8: Electricity purchase and energy cost versus RTP and battery size without energy cost limitation (analysis carried out in DER-CAM) 
(a)

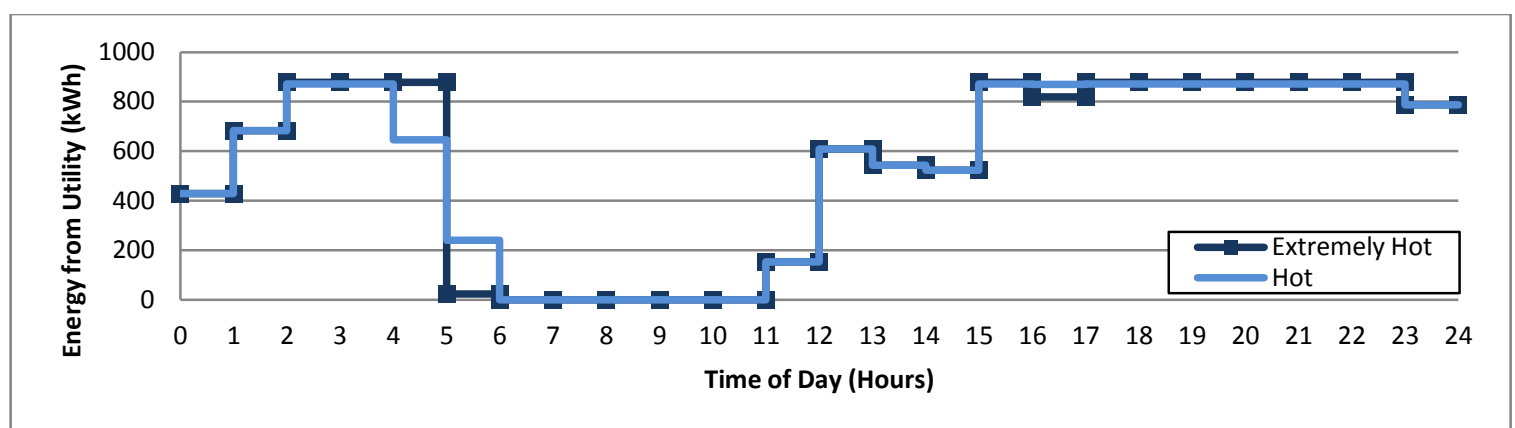

(b)

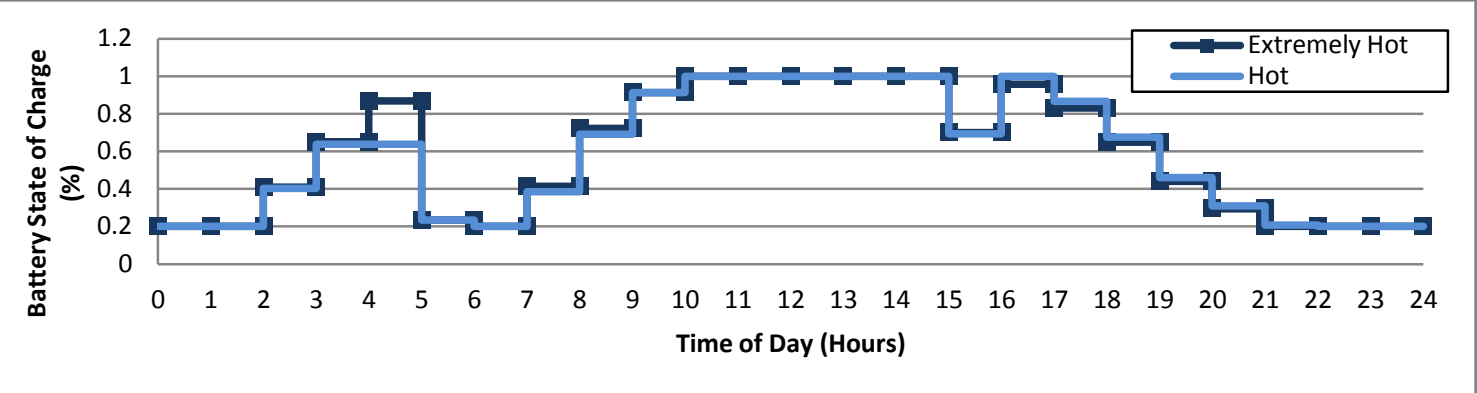

(a)

(b)

Figure 9: Comparison of optimal dispatch for extremely hot weather tariff vs. hot weather tariff, for a 1,000 kWh battery without energy cost limitation: (a) utility energy consumption, (b) battery state of charge

For a bigger battery, i.e., 5,000 kWh, Figure 8 shows that the customer is able to reduce the peak consumption, from 2,140 kWh for hot weather and very hot weather tariffs to 1,391 kWh for an extremely hot weather tariff. The difference between the optimal utility consumption and battery utilization strategy for hot and extremely hot weather tariffs are shown in Figure 10. Here, the customer uses more energy from the battery and less energy from the utility when the rates are very high.
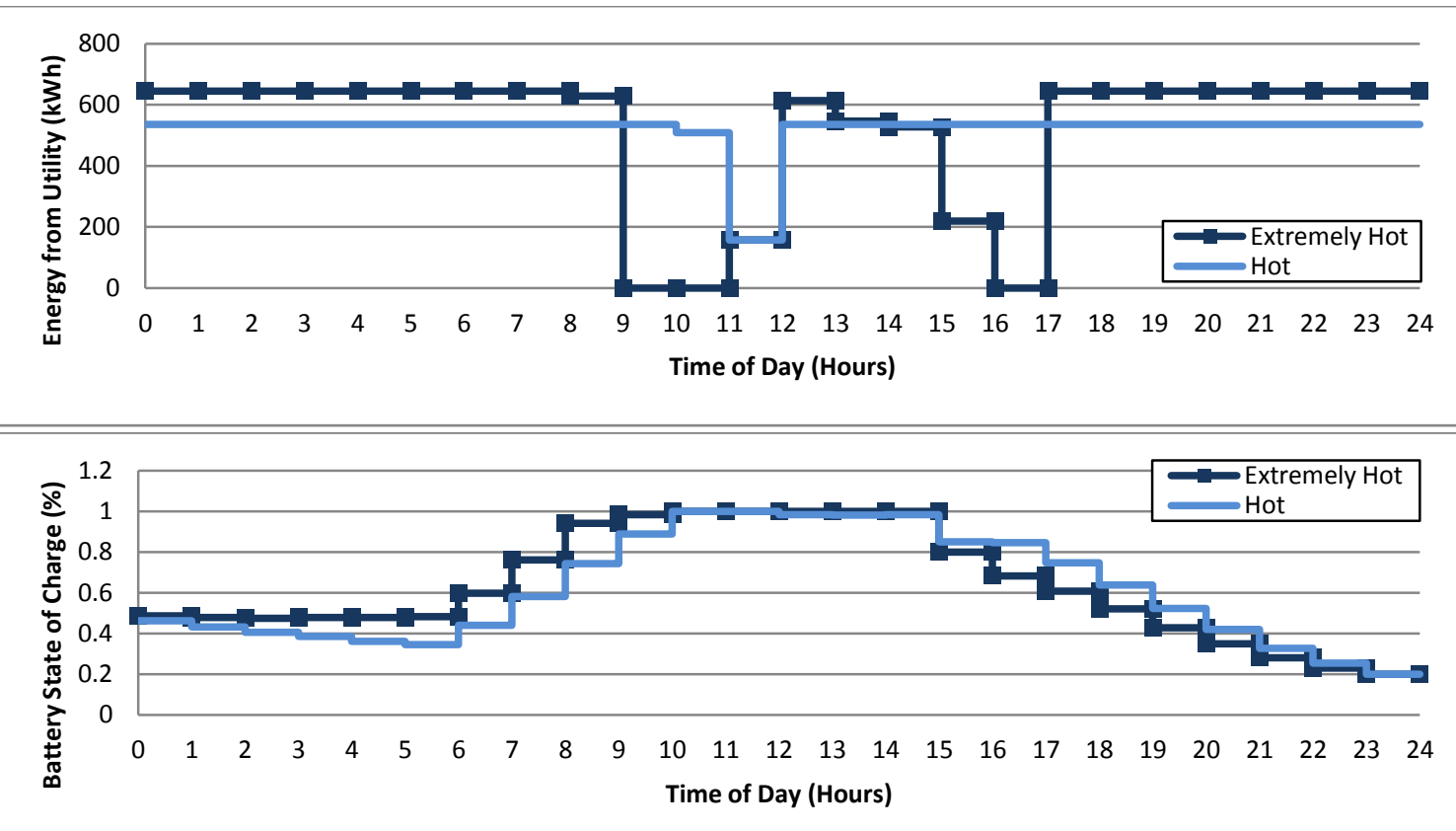

Figure 10: Comparison of optimal dispatch for extremely hot weather tariff vs. hot weather tariff, for a 5,000 kWh battery without energy cost limitation: (a) utility energy consumption, (b) battery state of charge. 


\subsubsection{Case Study with Daily Energy Cost Limit}

In the second set of studies, a maximum energy cost constraint was set for the optimization. The maximum energy cost was arbitrarily set to 1.5 times the daily energy cost with the baseline hot weather tariff. The load reduction was also allowed in this set of studies, and the maximum load reduction potential was set to 27 percent for the electrical and cooling loads, based on the load shed potential studies reported in Section 4.3. The summary of the results is shown in Figure 11. Note that the cases with hot weather tariff are the same as the ones in Figure 8, without the daily cost limit. Figure 11 shows that the electricity purchase from 2 pm- 6 pm decreases as energy rates increase from hot weather to very hot weather, and then to extremely hot weather tariffs. The load reduction increases as the energy rates increase. Table 2 shows the RTP energy costs in U.S. dollars (USD) and percent with respect to the hot weather tariff price for various cases. When the very hot weather tariff rates are used, the maximum energy cost limitation is met for all storage sizes. However, with extremely hot weather tariff rates with 1,000 and 2,000 kWh batteries, the energy cost goal cannot be satisfied, since the load reduction potential is not high enough. For a 5,000 kWh battery, however, this goal is met, and the daily energy cost is limited to 150 percent of the cost with the hot weather tariff.

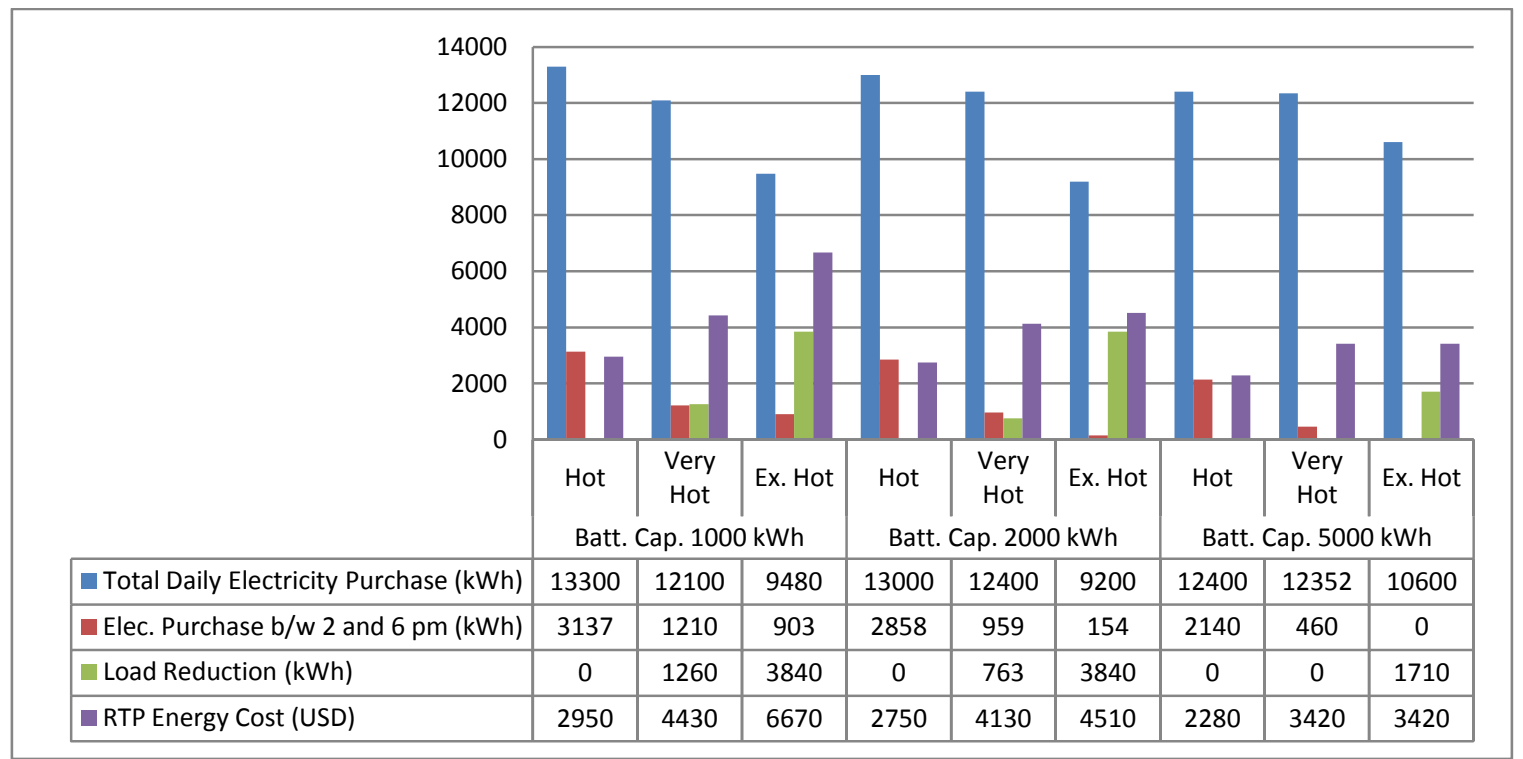

Figure 11: Electricity purchase and RTP energy cost versus RTP tariff day type and battery size with energy cost limitation (analysis carried out in DER-CAM)

Table 2: RTP energy cost for cases with energy cost limitation (analysis carried out in DER-CAM)

\begin{tabular}{|l|c|c|c|c|c|c|c|c|c|}
\hline Battery Size & \multicolumn{3}{|c|}{$1,000 \mathrm{kWh}$} & \multicolumn{3}{c|}{$2,000 \mathrm{kWh}$} & \multicolumn{3}{c|}{$5,000 \mathrm{kWh}$} \\
\hline RTP Day Type (Weather based) & Hot & Very Hot & Ex. Hot & Hot & Very Hot & Ex. Hot & Hot & Very Hot & Ex. Hot \\
\hline RTP Energy Cost (USD) & 2,950 & 4,430 & 6,670 & 2,750 & 4,130 & 4,510 & 2,280 & 3,420 & 3,420 \\
\hline RTP Energy Cost (\%) & $100 \%$ & $150 \%$ & $226 \%$ & $100 \%$ & $150 \%$ & $164 \%$ & $100 \%$ & $150 \%$ & $150 \%$ \\
\hline
\end{tabular}

Figure 12(a)-(c) compare the utility energy consumption, battery state of charge, and load reduction, respectively, between hot weather and extremely hot weather day type tariffs, when the battery capacity is 5,000 kWh and the energy cost is limited. Figure 12(c) shows that in this case, the entire load reduction potential during high-energy- 
(a)

(b)

(c)

cost periods is not being used. However, as shown in Table 2, the energy cost goal is achieved since the battery is big enough to provide enough flexibility.
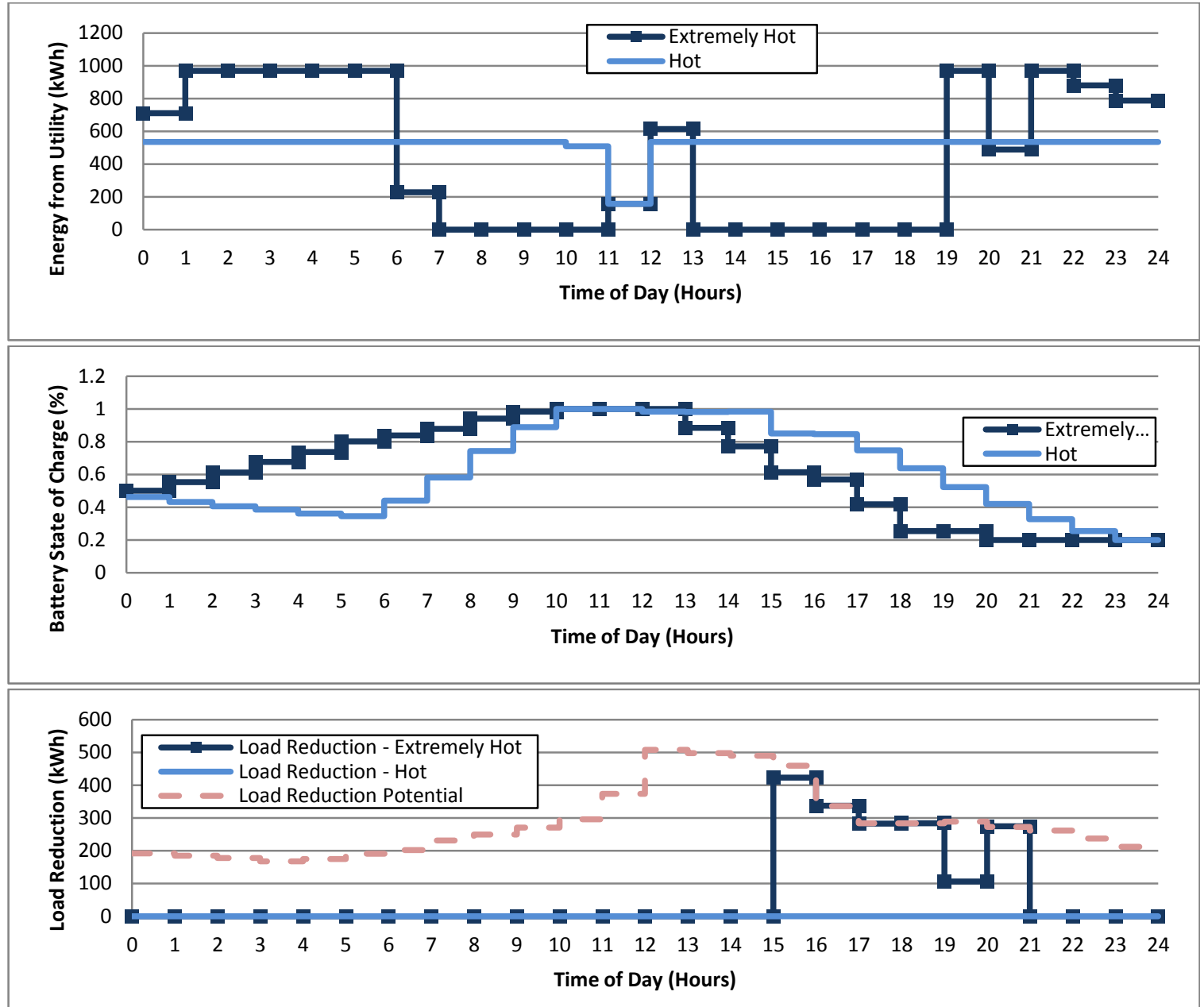

Figure 12: Comparison of optimum dispatch for extremely hot weather vs. hot weather tariffs, for a 5,000 kWh battery with energy cost limitation: (a) utility energy consumption (top), (b) battery state of charge (middle), (c) load reduction (bottom).

\subsection{Case Study Two - Optimization of DER and DR Integration for Peak Day Pricing}

For the PDP case studies, energy rates and demand charges based on SCE's TOU-8 CPP program were used [41]. In this program the customers receive a much lower regular on-peak demand charge (on-peak credit of $\$ 11.82 / \mathrm{kW} /$ month) if they participate in the PDP program. However, the energy rates during the on-peak period of a PDP day are much higher than the non-PDP rate $(\$ 1.37453 / \mathrm{kWh}$ more expensive than the non-PDP rate). Figure 13 compares the energy rates between peak and non-peak days and shows the enormous difference between the two rates during peak hours, e.g., 2 pm-6 pm. For the customer's baseline for an event day, a utility practice of "10-out-of-10" model was used. In this model the average of the customer's grid electricity consumption from the past 10 non-PDP-event weekdays (excluding weekends, holidays, and DR-event days) is used as the customer's baseline. 


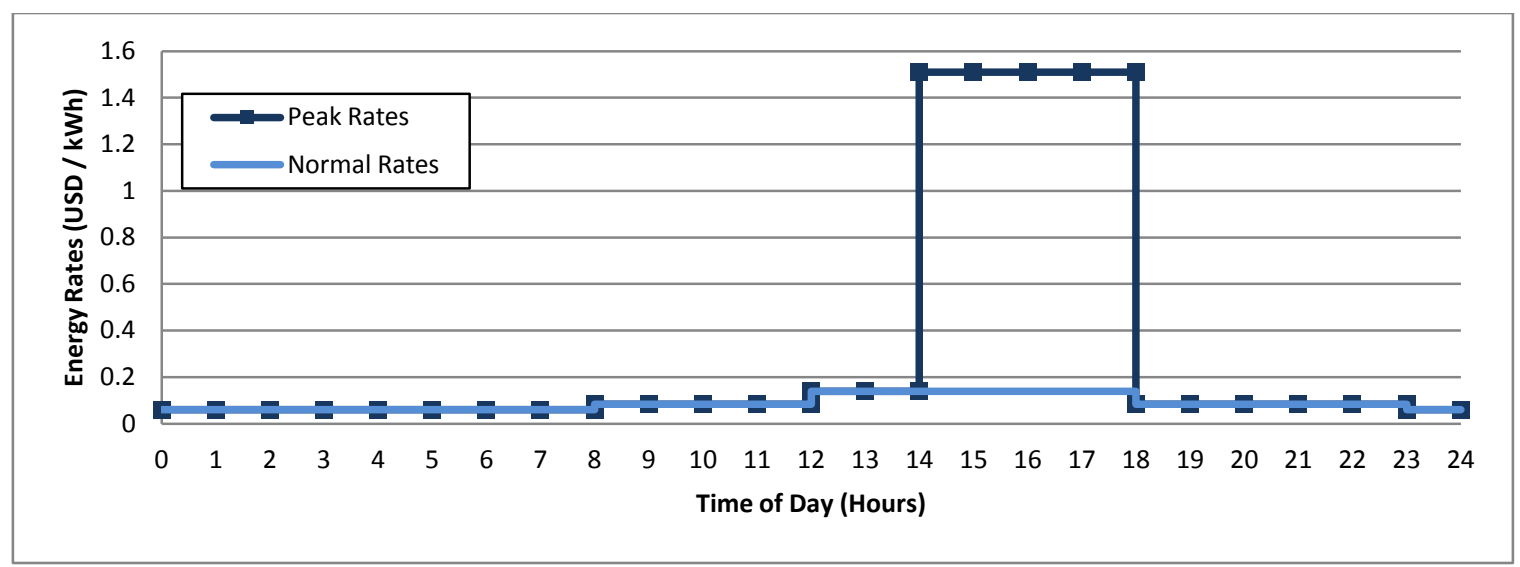

Figure 13: Comparison of energy rates between peak and non-peak days (PDP program)

To simulate a PDP event, we took the following steps: (1) chose a date; (2) used values from NREL's database for PV generation forecast for the chosen date; (3) used load values from a peak day in the considered month as the load forecast; (4) set the baseline during PDP hours; (5) ran the DER-CAM optimization and analyzed the results. To set the baseline during PDP hours: (1) a DER-CAM optimization was run for each of the past 10 non-weekend days; (2) for each of the 10 days, PV forecasts were generated using the NREL's database, and load forecasts were generated using the load values from a weekday in the month; and (3) the average of the electricity purchase for the 10 days was calculated, for each hour, as the baseline for that hour. Note that the on-peak, mid-peak, off-peak, coincidental, and non-coincidental power demands from these 10 days were also passed to the optimization for the PDP day. For the following studies, a summer day in July was chosen and assumed to be a PDP event day. The battery storage was assumed to be $1,000 \mathrm{kWh}$, which is the installed battery capacity at FHL.

Figure 14 shows the results for this case study. in Figure 14(a), the baseline for the utility consumption is shown with the dashed line, and the desired maximum load during the peak hours is shown with the thick green line. The desired maximum load is the baseline minus the desired reduction, which is about $53 \mathrm{kWh}$ per hour in this case. It can be observed that the load reduction goal was met during 2 pm-5 pm (the dark blue line matches the thick green line), but not during 5 pm-6 pm. To show the impact of peak day pricing on the customer's energy consumption, Figure 14(a) also depicts the utility purchase for this day if non-peak rates were to be used and shows that the utility purchase during peak hours would have been much higher with non-peak rates. This shows the effectiveness of the peak day prices on lowering the utility purchase of the customer. Figure 14(b) compares the battery state of charge for the peak rates with the non-peak case rates and shows that the battery state of charge (SOC) goes from fully charged to fully discharged (minimum charge) during peak hours when the peak rates are used. Figure 14(c) shows that the entire system's load reduction capacity is being used during $2 \mathrm{pm}-6 \mathrm{pm}$. However, the system is still not able to deliver the expected reduction during 5 pm-6 pm, as shown in Figure 14(a). 
(a)

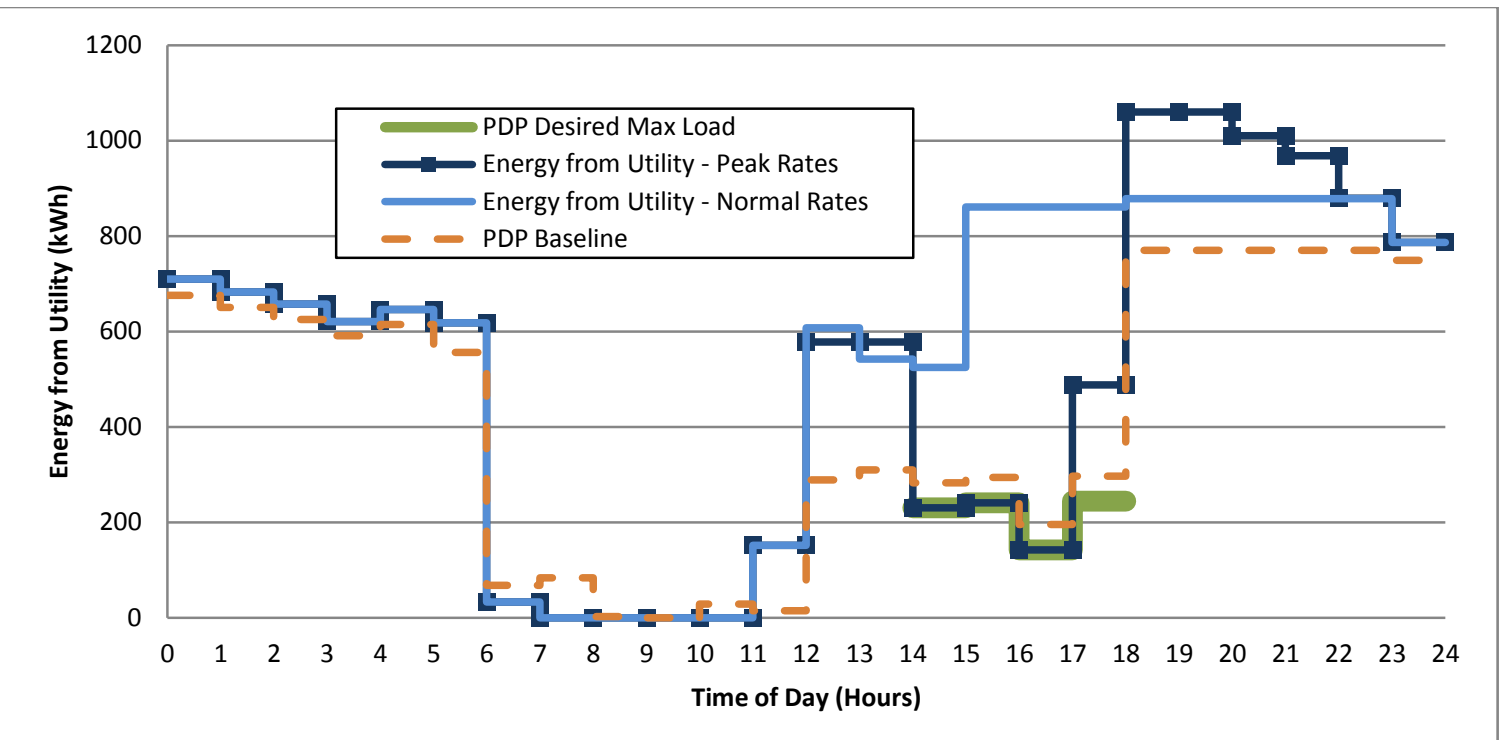

(b)

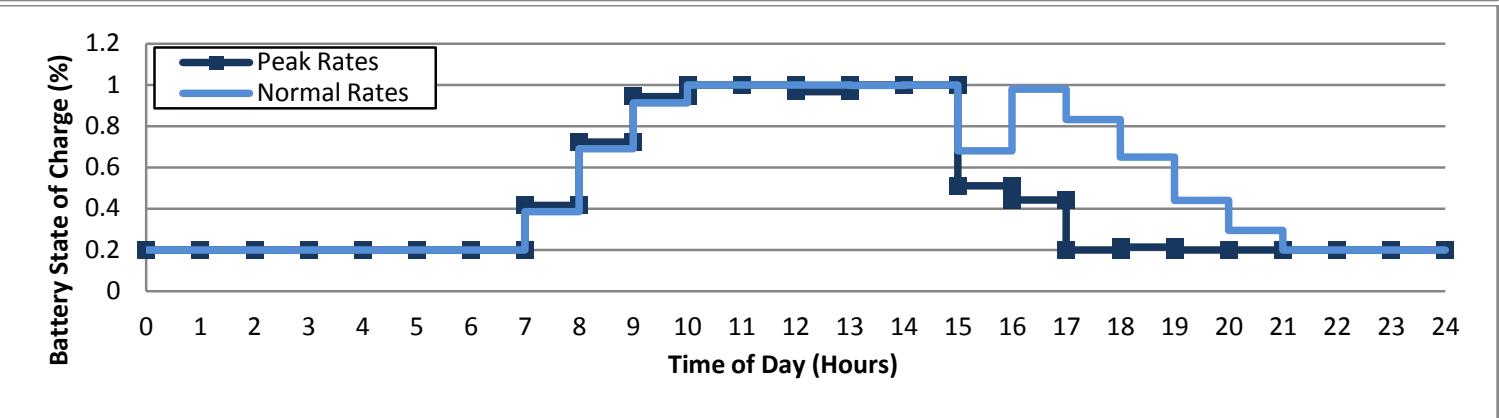

(c)

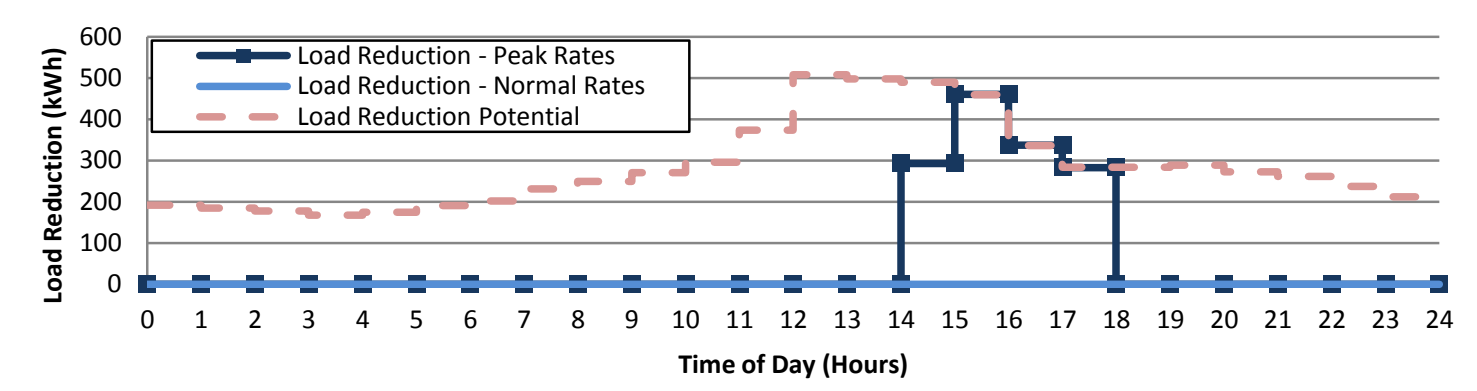

Figure 14: Comparison of optimal dispatch for peak vs. normal weekday tariffs, with a 1,000 kWh battery: (a) utility energy consumption, (b) battery state of charge, (c) load reduction (analysis carried out in DER-CAM)

The optimization run times for the RTP and PDP cases presented above were very short. In these examples, each optimization, covering one day of operation, took only several seconds to solve. The short solution time is because of DER-CAM's MILP model, and efficiency of solvers, e.g. CPLEX, for this type of optimization problems.

\section{Conclusions and Future Research}

In this study we evaluated the role of distributed energy resources (DER) and demand response (DR) to enable better integration and optimization for variable renewable energy generation resources and electric grid transactions. In particular, the current market design and systems integration do not consider and leverage the opportunity to improve reliability and persistency of DR from customers with DER infrastructure. Our simulation and demonstration results for an actual facility show that an integrated system with DR schedule and availability 
can provide reliable and persistent DR for different timescales of electricity markets. This understanding is critical for the next generation grid and to utilize customer-side DER to participate in electricity market programs.

The results show that we can optimize the DER dispatch for electric grid transactions using a dynamic model-inthe-loop analysis and open interoperable smart grid standards as OpenADR. Such models can be optimized for cost, energy, and carbon choices determined by the customers to identify demand flexibility. While we used mostly existing and known technologies, standards, and tools, the models can be applied to any similar DER operation schemes. They can be used with DR programs and future transactive energy concepts to enable continuous interactions between the electricity grid and customers.

We identified new DER optimization equations and implemented them to:

- enforce a maximum daily energy cost constraint, set by the customer; this maximum can also be extrapolated from customer's annual energy cost constraints,

- inform a customer's ability to meet daily energy cost constraints by optimized operation of loads and DER,

- accommodate load change constraints (increase or decrease) for utility prices; in case of PDP, these features can be applied against load decrease scenarios, and

- indicate if customer(s) can meet the load change constraints by optimized management of loads and DER.

The daily cost constraints and customer's comfort or facility operation depends on the magnitude and the willingness of service-level changes. A key achievement of this work has been the integration of existing DR systems and standards deployed by electricity service providers for dynamic optimization of DER and their gridinterconnection for DR services. The new feedback models in OpenADR provide continuous optimization, status, and availability of customer resources for requested DR. The feedback models from customers to DER service providers include:

- customer's daily utility or grid electricity purchase profiles for next 24 hours; this information can be used to reliably measure the individual or aggregated demand, and

- average DR load changes against a baseline used by the utility.

The customer response strategies to RTP or PDP developed in this project would provide customers with techniques to optimize DER scheduling and operations, as well as for participation in the future transactive energy (TE) markets for grid reliability. The TE refers to, "the use of a combination of economic and control techniques to improve grid reliability and efficiency." In this hypothetical framework, the customer can be provided with several sets of electricity prices for the next day and will return its forecasted next-day consumption based on each price set. Hence, from the customer's optimization formulation point of view, the transactive energy framework can be seen as an iterative RTP or PDP framework demonstrated in this work. Integrated energy systems, communication networks, and modeling tools that coordinate supply-side networks and DER will maximize enable electric grid system operators to use the DER for grid transactions as an integrated system. This study will help electricity service providers and customers to:

- identify existing standardized interfaces for AutoDR and use that infrastructure to integrate and optimize DER to provide load flexibility resources between the customer and distributed generation domains,

- enable a cost-effective AutoDR technology infrastructure and its interoperability with DER systems,

- reduce the electricity service provider's costs to implement, control, and manage DER for demand response markets, by eliminating additional capacity and transmission lines, and better enabling renewable energy integration, and

- enable customers with future choices through appropriate rate design and not through direct commandand-control. 


\subsection{Future Research and Development}

The modeling and demonstration of scheduled resources based on the model-in-the-loop simulations and use of open standards can be calibrated further by field tests and their applications in electric grid systems. OpenADR reporting services, which provide standardized representations of customer energy usage information at different timescales, can be used for baseline calculations and telemetry requirements of the wholesale DR markets. Addition of new feedback models from DER optimization can lead to their application in future transactive markets and utilization of customer-side DER for grid transactions. Future studies should consider the following:

- Improvement in the accuracy of results: The results should be confirmed in different customer sectors and field tests, under different DER operation scenarios, and customer flexibility parameters to leverage the value of participating in DR and transactive energy markets.

- Study of the impacts of forecasting errors: Currently, the planning and optimization are based on forecasting, and there are errors associated, but not handled explicitly. Incorporation with risk management will greatly complement the system.

- Cost-effective integrated system and power system communications: Enhanced understanding of power system and communication architecture for two-way information exchange, as well as storage costs, will influence the economic value of DER interconnection in electricity markets and their applications in future transactive energy markets.

- Incorporate disutility from load reduction: The current framework does not include any disutility from load reduction, e.g., temperature set point increase. To better uncover the trade-off between electricity cost and comfort of residents, the disutility could be added to the current objective function.

\section{Acknowledgments}

The work described in this report was coordinated by Lawrence Berkeley National Laboratory and funded under Work for Others Contracts and by the U.S. Department of Energy under Contract No. DE-AC02-05CH11231. The authors acknowledge all those who assisted in review of this document, and for their ongoing support.

\section{References}

[1] California Energy Commission (2015), "Renewable Portfolio Standards," Available: http://www.energy.ca.gov/portfolio.

[2] California Public Utilities Commission (2015), "Electric Rule No. 21," Available: http://www.cpuc.ca.gov/PUC/energy/rule21.htm.

[3] R. Masiello, K. Vu, L. Deng, A. Abrams, K. Corfee, J. Harrison, D. Hawkins, and Y. Kunjal, "Research Evaluation of Wind and Solar Generation, Storage Impact, and Demand Response on the California Grid," California Energy Commission, CEC-500-2010-010, 2010.

[4] California Energy Commission (2014), "Summary of Renewable Energy Installations Current and Planned in California," Available: www.energy.ca.gov/renewables/tracking_progress/documents/renewable.pdf.

[5] G. Ghatikar, D. Riess, and M. A. Piette, "Analysis of Open Automated Demand Response Deployments in California and Guidelines to Transition to Industry Standards," Lawrence Berkeley National Lab, LBNL6560E, 2014.

[6] "California Statewide Automated Demand Response Program," Opinion Dynamics, CALMAC Study ID SDG0277.01, March 2014.

[7] W. Greg, et al., "Pacific Gas \& Electric Company 2007 Auto-DR Program: Task 13 Deliverable: Auto-DR Assessment Study," PG\&E, 2008.

[8] M. A. Piette, G. Ghatikar, S. Kiliccote, D. Watson, E. Koch, and D. Hennage, "Design and Operation of an Open, Interoperable Automated Demand Response Infrastructure for Commercial Buildings," Journal of Computing and Information Science in Engineering, vol. 9, pp. 021004-021004, 2009. 


\begin{tabular}{|c|c|c|}
\hline 659 & [9] & Microgrids Evolution Roadmap - Working Group C6.22," CIGRE Working Group C6.22, 2012. \\
\hline 660 & [10] & E. Kuznetsova, Y.-F. Li, C. Ruiz, and E. Zio, "An integrated framework of agent-based modelling and robust \\
\hline 661 & & ptimization for microgrid energy management," Applied Energy, vol. 129, pp. 70-88, 2014. \\
\hline 662 & [11] & M. Elsied, A. Oukaour, H. Gualous, and R. Hassan, "Energy management and optimization in microgrid \\
\hline 663 & & ystem based on green energy," Energy, vol. 84, pp. 139-151, 2015. \\
\hline 664 & [12] & . Tenfen and E. C. Finardi, "A mixed integer linear programming model for the energy management \\
\hline 665 & & roblem of microgrids," Electric Power Systems Research, vol. 122, pp. 19-28, 2015. \\
\hline 666 & [13] & A. Rezvani, M. Gandomkar, M. Izadbakhsh, and A. Ahmadi, "Environmental/economic scheduling of a \\
\hline 667 & & micro-grid with renewable energy resources," Journal of Cleaner Production, vol. 87, pp. 216-226, 2015. \\
\hline 668 & [14] & A. Mohamed and H. N. Koivo, "Multiobjective optimization using Mesh Adaptive Direct Search for \\
\hline 669 & & power dispatch problem of microgrid," Intern \\
\hline 670 & & pp. 728-735, 2012. \\
\hline 671 & [15] & G.-C. Liao, "Solve environmental economic dispatch of Smart MicroGrid containing distributed generation \\
\hline 672 & & system - Using chaotic quantum genetic algorithm," International Journal of Electrical Power \& Energy \\
\hline 673 & & Systems, vol. 43, pp. 779-787, 2 \\
\hline 674 & [16] & E. Alvarez, A. M. Campos, P. Arboleya, and A. J. Gutiérrez, "Microgrid management with a quick response \\
\hline 675 & & optimization algorithm for active power dispatch," International Journal of Electrical Power \& Energy \\
\hline 676 & & Systems, vol. 43, pp. 465-473, 2012. \\
\hline 677 & [17] & R. Palma-Behnke, C. Benavides, F. Lanas, B. Severino, L. Reyes, J. Llanos, and D. Saez, "A Microgrid Energy \\
\hline 678 & & Management System Based on the Rolling Horizon Strategy," IEEE Transactions on Smart Grid, vol. 4, pp. \\
\hline 679 & & $996-10$ \\
\hline 680 & [18] & J. Quanyuan, X. Meidong, and G. Guangchao, "Energy Management of Microgrid in Grid-Connected and \\
\hline 681 & & Stand-Alone Modes," IEEE Transactions on Power Systems, vol. 28, pp. 3380-3389, 2013. \\
\hline 682 & [19] & A. Pantoja and N. Quijano, "A Population Dynamics Approach for the Dispatch of Distributed Generators," \\
\hline 683 & & IEEE Transactions on Industrial Electronics, vol. 58, pp. 4559-4567, 2011. \\
\hline 684 & [20] & D. E. Olivares, Can, x, C. A. izares, and M. Kazerani, "A Centralized Energy Management System for \\
\hline 685 & & Isolated Microgrids," IEEE Transactions on Smart Grid, vol. 5, pp. 1864-1875, 2014. \\
\hline 686 & [21] & Z. Binyan, S. Yi, D. Xiaodai, L. Wenpeng, and J. Bornemann, "Short-Term Operation Scheduling in \\
\hline 687 & & Renewable-Powered Microgrids: A Duality-Based Approach," IEEE Transactions on Sustainable Energy, vol. \\
\hline 688 & & 5, pp. 2 \\
\hline 689 & [22] & H. Kanchev, F. Colas, V. Lazarov, and B. Francois, "Emission Reduction and Economical Optimization of an \\
\hline 690 & & Urban Microgrid Operation Including Dispatched PV-Based Active Generators," IEEE Transactions on \\
\hline 691 & & Sustainable Energy, vol. 5, pp. 1397-1405, 2014. \\
\hline 692 & [23] & C. B. Jones, M. Robinson, H. Barsun, L. Ghanbari, A. Mammoli, S. Mashayekh, W. Feng, and C. Marnay, \\
\hline 693 & & "Software-as-a-Service Optimal Scheduling of New Mexico Buildings," in ECEEE 2015 Summer Study on \\
\hline 694 & & Energy Efficieny, France, 2015. \\
\hline 695 & [24] & M. Alipour, B. Mohammadi-Ivatloo, and K. Zare, "Stochastic risk-constrained short-term scheduling of \\
\hline 696 & & industrial cogeneration systems in the presence of demand response programs," Applied Energy, vol \\
\hline 697 & & pp. 393-404, 2014. \\
\hline 698 & [25] & Y.-H. Chen, S.-Y. Lu, Y.-R. Chang, T.-T. Lee, and M.-C. Hu, "Economic analysis and optimal energy \\
\hline 699 & & management models for microgrid systems: A case study in Taiwan," Applied Energy, vol. 103, pp. 145- \\
\hline 700 & & 54, 2013. \\
\hline 701 & [26] & D. McLarty, C. Civit Sabate, J. Brouwer, and F. Jabbari, "Micro-grid energy dispatch optimization and \\
\hline 702 & & predictive control algorithms; A UC Irvine case study," International Journal of Electrical Power \& Energy \\
\hline 703 & & Systems, vol. 65, pp. 179-190, 2015. \\
\hline 704 & {$[27]$} & H. Wu, X. Liu, and M. Ding, "Dynamic economic dispatch of a microgrid: Mathematical models and \\
\hline 705 & & solution algorithm," International Journal of Electrical Power \& Energy Systems, vol. 63, p \\
\hline 706 & & 2014. \\
\hline 707 & [28] & T. Niknam, R. Azizipanah-Abarghooee, and M. R. Narimani, "An efficient scenario-based stochastic \\
\hline 708 & & programming framework for multi-objective optimal micro-grid operation," Applied Energy, vol. 99, pp. \\
\hline 709 & & \\
\hline
\end{tabular}


[29] G. Cardoso, M. Stadler, A. Siddiqui, C. Marnay, N. DeForest, A. Barbosa-Póvoa, and P. Ferrão, "Microgrid reliability modeling and battery scheduling using stochastic linear programming," Electric Power Systems Research, vol. 103, pp. 61-69, 2013.

[30] C. Marnay, N. DeForest, M. Stadler, J. Donadee, C. Dierckxsens, G. Mendes, J. Lai, and G. Cardoso, "A Green Prison: Santa Rita Jail Creeps Towards Zero Net Energy (ZNE)," in ECEEE Summer Study, France, 2011.

[31] A. Mammoli, M. Stadler, N. Deforest, H. Barsun, R. Burnett, and C. Marnay, "Software-as-a-Service Optimised Scheduling of a Solar-Assisted HVAC System with Thermal Storage," 2013.

[32] A. Rabl and L. Norford, "Peak load reduction by preconditioning buildings at night," International Journal of Energy Research, vol. 15, pp. 781-798, 1991.

[33] F. Morris, J. E. Braun, and S. Treado, "Experimental and simulated performance of optimal control of building thermal storage," \{ASHARE\} Transactions, vol. 100, pp. 402-414, 1994.

[34] P. Xu, P. Haves, M. A. Piette, and J. Braun, "Peak demand reduction from pre-cooling with zone temperature reset in an office building," in ACEEE Summer Study of Energy Efficiency in Buildings, 2004.

[35] R. Yin, P. Xu, M. A. Piette, and S. Kiliccote, "Study on Auto-DR and pre-cooling of commercial buildings with thermal mass in California," Energy and Buildings, vol. 42, pp. 967-975, 2010.

[36] US Department of Energy (2015), "EnergyPlus Energy Simulation Software," Available: http://apps1.eere.energy.gov/buildings/energyplus.

[37] N. Motegi, M. A. Piette, D. S. Watson, S. Kiliccote, and P. Xu, "Introduction to commercial building control strategies and technologies for demand response," Lawrence Berkeley National Lab, LBNL-59975, 2007.

[38] G. Ghatikar and R. Bienert, "Smart grid standards and systems interoperability: a precedent with OpenADR," in proceedings of the Grid Interop Forum, 2011.

[39] M. A. Piette, S. Kiliccote, and G. Ghatikar, "Field Experience with and Potential for Multi-time Scale Grid Transactions from Responsive Commercial Buildings," in ACEEE Summer Study on Energy Efficiency in Buildings, 2014.

[40] M. A. Piette, "Automated Measurement and Signaling Systems for the Transactional Network," Lawrence Berkeley National Lab, LBNL-6611E, 2013.

[41] Southern California Edison (2015), "Schedule TOU-8-RTP, General Service - Large, Critical Peak Pricing," Available: https://www.sce.com/NR/sc3/tm2/pdf/ce54-12.pdf.

[42] Southern California Edison (2015), "Schedule TOU-8-RTP, General Service - Large, Real Time Pricing," Available: https://www.sce.com/NR/sc3/tm2/pdf/ce78-12.pdf.

[43] Southern California Edison (2015), "Real-Time Pricing (RTP): How Much You Save Is Up To You," Available: https://www.sce.com/wps/wcm/connect/04ae933b-cafa-4412-bbe48a1ab443f81c/RTP\%2BFACT\%2BSheet NR-2225-V1-0413.pdf?MOD=AJPERES.

[44] Pacific Gas and Electric (2015), "Rate Schedule E19 "Available: http://www.pge.com/tariffs.

[45] G. Cardoso, M. Stadler, M. C. Bozchalui, R. Sharma, C. Marnay, A. Barbosa-Póvoa, and P. Ferrão, "Optimal investment and scheduling of distributed energy resources with uncertainty in electric vehicle driving schedules," Energy, vol. 64, pp. 17-30, 2014.

[46] "Addressing Implementation of a Net Zero Program at Fort Hunter Liggett, California," HDR, 2014. Available: http://www.liggett.army.mil/pdf/dpwPDF/Env/FHL\%20Net\%20Zero Draft\%20EA 081214.pdf.

[47] National Renewable Energy Lab (2014), "Solar Power Data for Integration Studies," Available: http://www.nrel.gov/electricity/transmission/solar integration methodology.html.

[48] G. Cardoso, M. Stadler, M. C. Bozchalui, R. Sharma, C. Marnay, A. Barbosa-Póvoa, and P. Ferrão, "Optimal investment and scheduling of distributed energy resources with uncertainty in electric vehicle driving schedules," Energy, vol. 64, pp. 17-30, 2014.

[49] G. Cardoso, M. Stadler, A. Siddiqui, C. Marnay, N. DeForest, A. Barbosa-Póvoa, and P. Ferrão, "Microgrid reliability modeling and battery scheduling using stochastic linear programming," Electric power systems research, vol. 103, pp. 61-69, 2013.

[50] M. Stadler, M. Groissböck, G. Cardoso, and C. Marnay, "Optimizing Distributed Energy Resources and building retrofits with the strategic DER-CAModel," Applied Energy, vol. 132, pp. 557-567, 2014.

[51] M. Stadler, M. Kloess, M. Groissböck, G. Cardoso, R. Sharma, M. C. Bozchalui, and C. Marnay, "Electric storage in California's commercial buildings," Applied Energy, vol. 104, pp. 711-722, 2013. 

Automated Demand Response Communications Specification (Version 1.0)," California Energy Commission, PIER Program, CEC-500-2009-063, 2009.

\section{Appendices}

\section{Appendix A - Distributed Energy Resources Customer Adoption Model (DER-CAM)}

DER-CAM is a flexible decision-support tool for decentralized integrated energy systems, and has two major versions: (1) Investment \& Planning DER-CAM determines the optimal investment portfolio of DERs based on cost and performance characteristics, tariff information, and historic/simulated hourly load and PV generation data, for a given building, campus, or microgrid; (2) Operations DER-CAM provides detailed optimized operation schedules for existing DERs in a building or microgrid on a week-ahead basis, using forecasted loads and weather data. In this study, Operations DER-CAM was adapted and used.

A high-level schematic of the energy flow in DER-CAM, in the form of a Sankey diagram, is shown in Figure 15. This figure shows how purchased energy as well as energy generated locally through renewable or non-renewable resources (input energies are shown on the left hand side), is used to meet the loads (loads are shown on the right hand side) in various end-uses. It also shows how energy can be converted from one form to another. DER-CAM is mathematically modeled as a Mixed Integer Linear Program [48-51] and is based on the key premise that all thermal and electrical loads are served, although specific actions leading to load shedding can also be considered.

\section{MICROGRID ARCHITECTURE AND DECISION-MAKING}

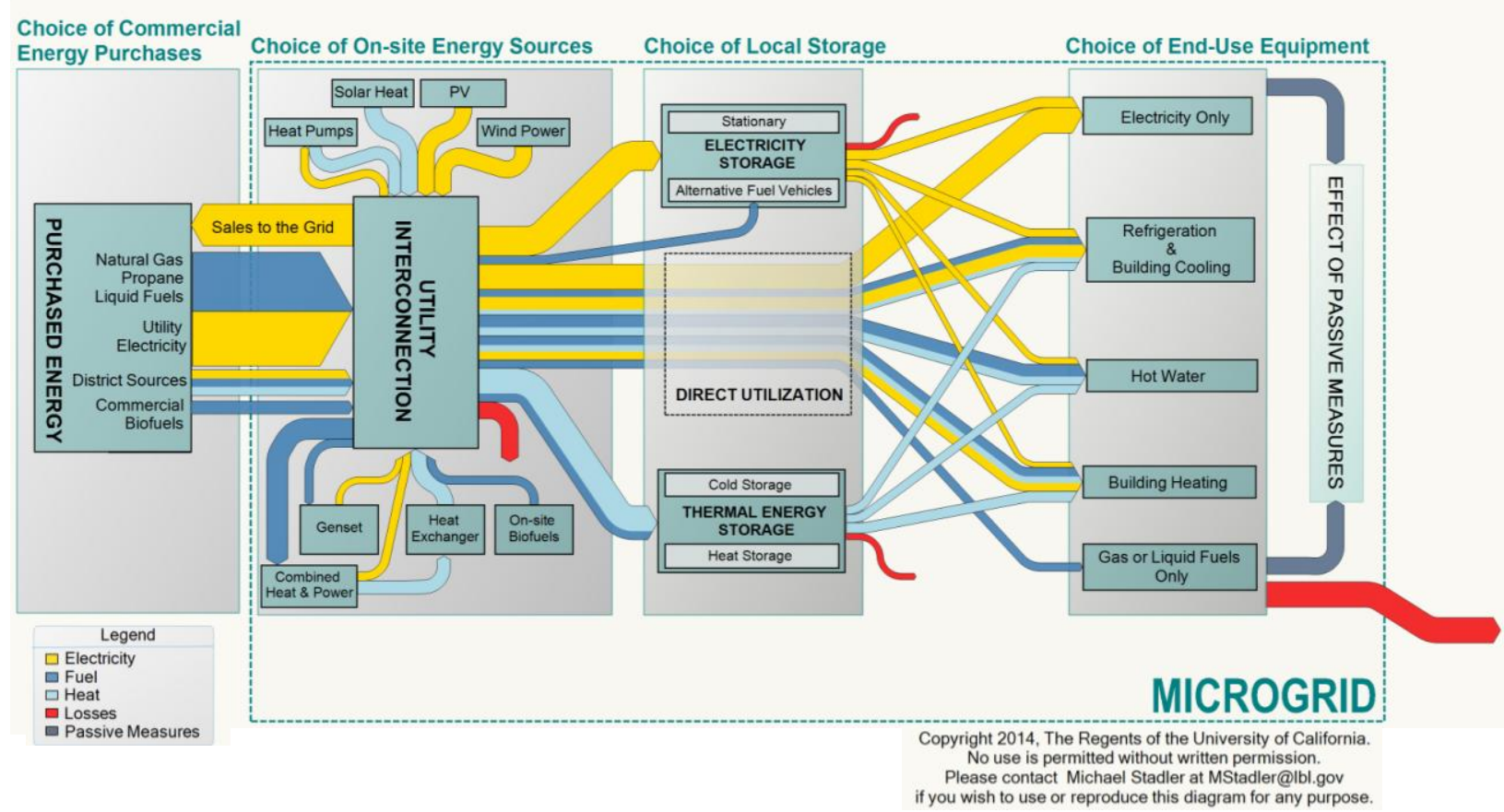

Figure 15: Schematic of the Energy Flow Model used in DER-CAM

\section{Appendix B - Demand Response Strategies and End Use Systems Integration Using DRQAT}

Table 3 below presents the summary of DR strategies in field test case studies [37]. In this study, we characterized DR control strategies for various end use systems at three operation levels (low, medium, and high) for different building types. 


\begin{tabular}{|c|c|c|c|c|c|c|c|c|c|c|c|c|c|c|c|c|c|c|}
\hline $\begin{array}{l}\text { Building } \\
\text { Use }\end{array}$ & 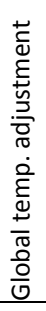 & 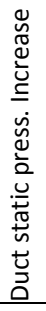 & 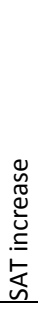 & 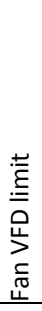 & 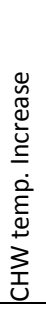 & 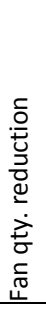 & 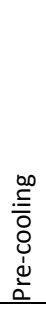 & 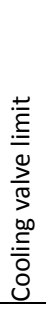 & 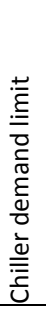 & 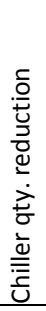 & 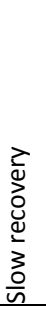 & 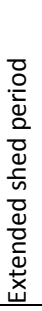 & 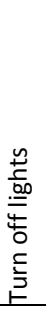 & 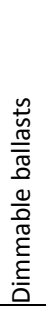 & 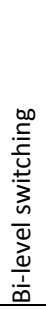 & 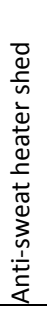 & 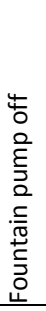 & 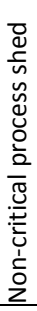 \\
\hline Office, lab & $X$ & $X$ & $X$ & & $X$ & & & $X$ & & & & $X$ & & & & & & \\
\hline $\begin{array}{l}\text { Office, } \\
\text { data } \\
\text { center }\end{array}$ & & $X$ & $X$ & $X$ & $X$ & & & $X$ & & & & & & & & & & \\
\hline Office & $X$ & & $X$ & & & & $X$ & & & & $X$ & & & & & & & \\
\hline Office & $X$ & & $X$ & & & & & & & & $X$ & & $X$ & & & & & \\
\hline $\begin{array}{l}\text { High } \\
\text { School }\end{array}$ & $X$ & & & & & & X & & & & & & & & & & & \\
\hline Retail & $X$ & & & & & $X$ & & & & & & & & & $X$ & & & \\
\hline $\begin{array}{l}\text { Super } \\
\text { Market }\end{array}$ & & & & & & & & & & & & & & & $X$ & & & \\
\hline Bakery & & & & & & & & & & & & & & & & & & $X$ \\
\hline Manufac. & $X$ & & & & & $X$ & & & & & & & & & $X$ & & & \\
\hline
\end{tabular}

Note: SAT (Supply Air Temperature), VFD (Variable Frequency Drive), CHW (Chilled Water)

\section{Appendix C - Open Automated Demand Response Standards [38]}

OpenADR provides non-proprietary, standardized interfaces to enable electricity service providers to communicate DR and Distributed Energy Resource (DER) signals to customers using a common language and existing communications such as the Internet [52]. These OpenADR data models facilitate price-responsive and reliability DR. As shown in Figure 16 below, this is achieved through open Application Programming Interfaces (APIs) that provide two-way communications between the service provider (Utility/ISO) and customers (Sites) through a logical interface of an OpenADR server (called a Demand Response Automation Server).

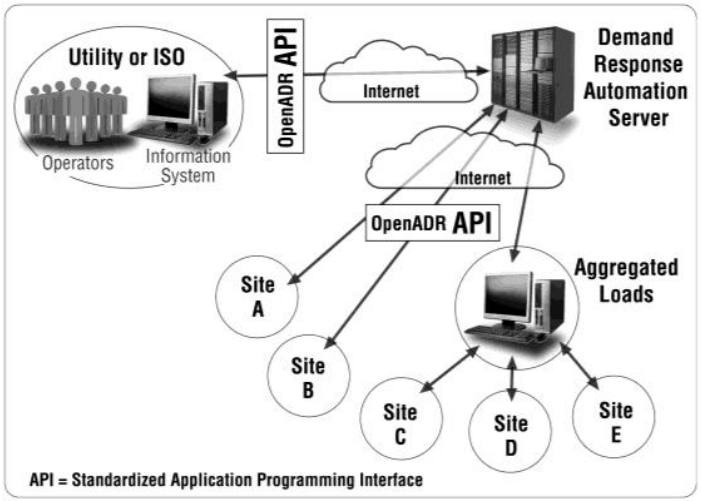

Figure 16: OpenADR Communication Architecture

The communications between the service providers and consumers in OpenADR 2.0 have evolved generically as the Virtual Top Node (VTN) and the Virtual End Node (VEN), respectively. The VTN/VEN pair structure allows a chain of hierarchy from the parent (the one that issues primary DR signal) to the multiple parent/child relationships all the way to the end-use devices. 